\title{
EL DESARROLLO DE LAS INMUNIDADES DE LAS ORGANIZACIONES INTERNACIONALES A TRAVÉS DE LAS CONTESTACIONES NACIONALES
}

\section{Mateja Steinbrück Platise ${ }^{1}$}

RESUMEN: El goce de las inmunidades jurisdiccionales de las organizaciones internacionales se basa, sobre todo, en su necesidad funcional. Los tribunales nacionales enfrentan un dilema. Pueden respetar dicha inmunidad o garantizar el acceso a un recurso jurídico a las personas afectadas por un hecho ilícito cometido por una organización.

Palabras clave: Organizaciones Internacionales, Inmunidad furisdiccional, Mecanismos Alternativos de Solución de Controversias, Iure Imperii, Iure Gestionis.

ABSTRACT: The development of the immunities of international organizations is based on functional necessity. In this context, domestic courts are faced with two conflicting obligations under international law: the inmunities of international organisations or the access to justice as a human right.

KEY WORDS: International Organizations, furisdictional Immunity, Alternative Dispute Resolution, Iure Imperii, Iure Gestionis.

SUMARIO: I. Introducción; II. La expansión de las peticiones de inmunidad por parte de las OI; III. Contestaciones de los tribunales nacionales; IV. Recepción en el derecho internacional. v. Esbozando un marco normativo para la interacción entre las cortes nacionales y las instituciones internacionales.

1 Profesora de la Universidad de Heidelberg, Alemania. Traducción de Octavio Vara, al cuidado de la autora. 


\section{INTRODUCCIÓN}

7 or mucho tiempo, el derecho internacional reguló campos de las actividades sociales altamente especializados y bien definidos. Una gran parte de ellos consistían en obligaciones convencionales técnicas específicamente delimitadas que se referían a asuntos exteriores con una significancia política baja: las relaciones diplomáticas y consulares, la entrega internacional del correo, la aviación internacional, entre otros. ${ }^{2}$ Las normas y estándares internacionales, incluyendo aquellas adoptadas por los organismos internacionales, se dirigían primordialmente a los Estados. Así, a las organizaciones internacionales (OI) se les encomendaron actividades limitadas, por lo que empleaban relativamente pocos funcionarios. Por consiguiente, en situaciones donde las OI cometían actos ilícitos, dichos actos se constreñían a los campos reducidos de sus actividades y afectaban directamente a un número restringido de individuos y otras entidades privadas. Como resultado, en raras ocasiones fueron presentadas demandas en contra de las OI en los tribunales nacionales. Cuando tales disputas surgían, las cortes lidiaban con ellas de manera casuística y la cuestión de las inmunidades jurisdiccionales de las OI en las cortes nacionales no fueron una preocupación mayor. ${ }^{3}$

Con el aumento en número y tamaño de las OI, las inmunidades comenzaron a ser reguladas a nivel internacional. Cuando la Organización de las Naciones Unidas (ONU) fue establecida,

2 Matthias Kumm, "The Legitimacy of International Law: A Constitutionalist Framework of Analysis" (2004), en 15 European Fournal of International Law 907, 912; Jan Klabbers, An Introduction to International Institutional Law (2a ed., Cambridge; Nueva York, Cambridge University Press, 2009) 14-20; Joseph H. H. Weiler, "The Geology of International Law: Governance, Democracy and Legitimacy" (2004), en 64 Zeitschrift für ausländisches öffentliches Recht und Völkerrecht 547, 549-552.

3 Michael Singer, "Jurisdictional Immunity of International Organizations: Human Rights and Functional Necessity Concerns" (1995), en 36 Virginia fournal of International Law 53, 59. 
las disposiciones de la Carta de la ONU concedían al organismo personalidad jurídica así como los privilegios e inmunidades necesarias para el cumplimiento de sus propósitos. ${ }^{4}$ Posteriormente, los alcances de esas inmunidades fueron establecidos en la Convención sobre Prerrogativas e Inmunidades de las Naciones Unidas, la cual establece que la organización "gozará de inmunidad contra todo procedimiento judicial a excepción de los casos en que renuncie expresamente a esa inmunidad". ${ }^{5}$ Los instrumentos constitutivos de otras OI y sus tratados de implementación contienen preceptos similares. ${ }^{6}$ Las disposiciones sobre el alcance de las inmunidades dieron origen a la doctrina de la "necesidad funcional", la cual propone que las OI gozan de esas inmunidades debido a que estas son necesarias para el ejercicio de sus funciones y el cumplimiento de sus objetivos y fines. ${ }^{7}$

Sin embargo, la práctica ha demostrado que las OI reivindican sus inmunidades ante las cortes nacionales sin a la vez someterse a algún mecanismo alternativo de solución de controversias para que se conozcan los reclamos presentados en su contra. Así, el recelo de las OI de resolver controversias con individuos y otras entidades privadas resulta en la privación sistemática de su acceso a recursos jurídicos, y usualmente los deja sin un foro en el que puedan di-

${ }^{4}$ Carta de las Naciones Unidas, 26 junio 1945, 1 UNTS XVI (en vigor 24 octubre 1945) (1945) Art. 105 (1). En el segundo párrafo, una disposición similar es añadida con respecto a los representantes de los Estados y los funcionarios de la ONU.

5 Convención sobre Prerrogativas e Inmunidades de las Naciones Unidas, 13 febrero 1946, 1 UNTS 15 (en vigor desde el 17 septiembre 1946) (1946) Art. 2(2).

6 Vid., por ejemplo: Convención sobre los Privilegios e Inmunidades de los Organismos Especializados, 33 UNTS 261 (en vigor desde el 2 diciembre 1948) Art. 3(4); Carta de la Organización de los Estados Americanos, 119 UNTS 3 Art. 133; Estatuto del Consejo de Europa, 87 U.N.T.S. 103, ETS 1 Art. 40.

7 Para una visión general desde el enfoque de la necesidad funcional, vid., Peter H. F. Bekker, The Legal Position of Intergovernmental Organizations: A Functional Necessity Analysis of Their Legal Status and Immunities (Dordrecht; Boston, M Nijhoff, 1994). 
rimir sus demandas, ya sea en el plano nacional o internacional. ${ }^{8}$ Asimismo, este recelo de las OI de dirimir conflictos presenta un dilema para las magistraturas locales, quienes se encuentran ante dos obligaciones internacionales en conflicto: por una parte, están obligadas a respetar las inmunidades de las OI; ${ }^{9}$ por otra parte, también deben garantizar el derecho de acceso a los tribunales y el derecho de los individuos y otras entidades privadas a un recurso jurídico. ${ }^{10}$ Además, el acceso a la justicia como un derecho humano es usualmente protegido a nivel constitucional y es parte esencial del Estado de Derecho. ${ }^{11}$ De este modo, las normas internacionales sobre las inmunidades de las OI pueden también contravenir el Estado de Derecho nacional, en el sentido de que todo ejercicio público de autoridad sobre los individuos y otras entidades privadas debería estar sometido a un control jurisdiccional. ${ }^{12}$

8 Para uno de los ejemplos más recientes vid., la declaración del Secretario General de la ONU de 21 de febrero de 2013 en donde se solicita inmunidad para la ONU en relación con el brote de cólera en Haití supuestamente causado por tropas de ONU, disponible en: <http://www.un.org/sg/statements/?nid=6615> (último acceso octubre 2013).

9 Además del derecho de los tratados, la obligación deriva parcialmente del derecho internacional consuetudinario y los principios generales del Derecho; vid., James Crawford, Brownlie's Principles of Principles of Public International Law (8a ed., Oxford, Oxford University Press, 2012) 652-655, con mayores referencias.

10 Sobre la obligación de otorgar inmunidades a las OI vid., la Sección II (A) del presente capítulo. Sobre la obligación de respetar el derecho de acceso a los tribunales y el derecho a un recurso, vid., la Sección III (A).

11 Sobre el derecho de acceso a los tribunales y el derecho a un recurso como derechos constitucionales vid., los ejemplos discutidos en las Secciones III (A) y (B).

12 Sobre la ausencia de un control jurisdiccional sobre los actos de las OI como parte de un problema general de legitimidad de las OI vid., Armin vON Bogdandy, Philipp Dann y Matthias Goldmann, "Developing the Publicness of Public International Law: Towards a Legal Framework for Global Governance Activities" en A. vOn Bogdandy, et al., (eds.), The Exercise of Public Authority by International Institutions: Advancing International Institutional Law (Springer, 2009) 1379-1380. 
En el presente capítulo, * en la sección II, analizaré primero algunos de los razonamientos teóricos y prácticos sobre las dificultades que el respeto de las inmunidades de las OI representa para las cortes nacionales. En particular, mostraré el conflicto que existe entre el aumento de los poderes y competencias de las OI, las cuales solicitan el respeto a las inmunidades absolutas ante las cortes nacionales, así como el rechazo de las OI a someterse a mecanismos alternativos de solución de controversias que puedan compensar la ausencia de jurisdicción por parte de los tribunales nacionales. En la sección III, examinaré cómo los tribunales nacionales responden a estas dificultades en el contexto del desarrollo de los derechos humanos y el derecho constitucional, en particular al cuestionar el alcance absoluto de las inmunidades de las OI. Los tribunales nacionales objeto de análisis fueron seleccionados en razón de la contribución que han aportado al desarrollo del derecho internacional en torno a las inmunidades de las OI. Los efectos producidos por la práctica de las cortes nacionales en el derecho internacional serán estudiados en la sección IV, donde me enfocaré en aquellos actores internacionales que han abordado el tema de la legalidad y legitimidad de las contestaciones judiciales nacionales al alcance absoluto de las inmunidades de las IO. Con base en el análisis de la práctica de las cortes nacionales realizado en la sección III y su recepción en el derecho internacional en la sección IV, en la sección $\mathrm{V}$ trataré de proponer un marco normativo bajo el cual los jueces de un Estado sean capaces de influenciar el desarrollo del derecho internacional en la materia y así participar activamente en su creación. Consecuentemente, trataré de señalar que, además del papel de los tribunales nacionales para asegurar el Estado de Derecho en el plano nacional, también deberá reconocerse su potencial para contribuir al Estado de Derecho a nivel internacional. Esta doble función podría prevenir que la autoridad pública

* El presente artículo forma parte de una obra conjunta. Vid., Kanetake, MAChiko y André Nollkaemper, (eds.) The Rule of Law at the National and International Levels: Contestations and Deference (Hart Publishing, Oxford). [N.T. ] 
ejercida sobre los individuos, ya sea a nivel local o supranacional, pueda escapar de un control jurisdiccional. A manera de conclusión, se valorará la relevancia de este desarrollo para la futura interacción entre las cortes nacionales con las instituciones internacionales, así como entre los ordenamientos jurídicos a los cuales los tribunales y las instituciones pertenecen.

II. LA EXPANSIÓN DE LAS PETICIONES DE INMUNIDAD POR PARTE DE LAS OI

1. Ausencia de diferenciación entre actos de iURE imperil Y DE IURE GESTIONIS

Mientras que un gran número de instrumentos ${ }^{13}$ otorgan inmunidades a las OI en la medida necesaria para el cumplimiento de sus propósitos, estos instrumentos no estipulan los actos que las OI pueden ejercer como parte de tales propósitos. En consecuencia, las interpretaciones sobre los alcances de las inmunidades han sido controvertidas y han conllevado a conclusiones diversas, e incluso contradictorias. Por una parte, las OI usualmente aseveran que únicamente las inmunidades absolutas cubren el requerimiento de la necesidad funcional. ${ }^{14}$ Por otra parte, las cortes nacionales han sido

13 Las normas relativas a los privilegios e inmunidades de las OI son en algunas ocasiones comparadas a un laberinto de tratados y otros instrumentos jurídicos, incluyendo a la legislación nacional, vid., KLABbers, An Introduction to International Institutional Law (nota 2) 155. Para una de las primeras discusiones de este problema, vid., David B Michaels, International Privileges and Immunities: A Case for a Universal Statute (La Haya, Martinus Nijhoff, 1971).

14 Vid., v. g., la petición de la Organización de Estados Americanos así como los informes amici curiae de la ONU, el Banco Internacional de Reconstrucción y Desarrollo, el Banco Interamericano de Desarrollo y la Organización Nacional de Telecomunicaciones Satelitales en el caso Broadbent v Organization of American States, Corte de Apelaciones de los EUA, 628 F 2d 27 (DC Cir 1980); Atkinson v Inter-American Development Bank, Sentencia de Apelación, 156 F 3d 1335 (DC Cir 1998); OSS Nokalva, Inc v European Space Agency, Sentencia de Apelación, 617F 3d 
mucho menos inequívocas al interpretar los alcances de esas inmunidades. ${ }^{15}$ Dichas interpretaciones han variado de un juzgador a otro, ${ }^{16}$ de un país a otro, ${ }^{17}$ y también han cambiado con el tiempo. ${ }^{18}$ Las cortes nacionales solían ser bastantes generosas al otorgar inmunidades absolutas a las OI, comúnmente bajo el argumento de que únicamente la protección más amplia podría asegurar su actuar independiente. De hecho, cuando las OI surgieron, a éstas se les había encomendado funciones limitadas, sus propósitos estaban bastantes definidos y mantenían una posición endeble vis-à-vis los Estados. ${ }^{19}$ Por lo tanto, para garantizarles un actuar independiente, sus inmunidades requerían de un alcance más amplio, generalmen-

756 (3 Cir 2010), vid., también la nota sobre el caso en ILDC 1580 (US 2010); Killeen v International Centre of Insect Physiology and Ecology, Primera instancia, Alta Corte de Nairobi, Caso Civil 1737 de 2002, para la nota del caso vid., ILDC 77 (KE 2005); General Secretariat of the African, Caribbean and Pacific Group of States v. BD, Corte Belga de Casación, Sentencia de apelación final, Cass nr C 070407 F, para el análisis del caso vid., ILDC 1576 (BE 2009).

15 Para un estudio general vid., August Reinisch, International Organizations Before National Courts (Cambridge; New York, Cambridge University Press, 2000) 206.

16 Cfr., v. g., las diferentes sentencias de las cortes neerlandesas sobre este caso: Mothers of Srebrenica $v$. the State of the Netherlands and the United Nations: Caso No. 295247/HA ZA 07-2973; Mothers of Srebrenica et. al. v. The State of the Netherlands and the United Nations (2008) (Países Bajos, Corte de Distrito en La Haya, Sentencia de 10 de julio de 2008); Caso No. 200022151/01 Mothers of Srebrenica et. al. v. The State of the Netherlands and the United Nations (2010) (Corte de Apelaciones de La Haya, sentencia de 30 de marzo de 2010); Mothers of Srebrenica v Netherlands and United Nations, sentencia final apelatoria (2012) LJN: BW1999; ILDG 1760 (NL 2012) (Países Bajos, Suprema Corte, 13 de abril de 2012). Vid., Sección IV del presente artículo.

17 Cfr., v. g., African Development Bank v Mr X, Corte Francesa de Casación, Sala de Apelaciones No. 04-41012, ILDG 778 (FR 2005) con Weinstock v Asian Development Bank and Others, Corte de Distrito de EUA, acción civil No. 1:05-GV00174, 13 de julio de 2005, (EUA 2005).

18 Sobre la jurisdicción de los EUA, $c f r$. el anterior precedente en el caso Atkinson con el nuevo precedente establecido en el caso Nokalva (nota 14).

19 G. Wilfred Jenks, International immunities. (Londres; New York, Stevens; Oceana Publications, 1961) 40-41. 
te absoluto. Igualmente, de manera tradicional, las inmunidades de las IO también fueron asimiladas con las inmunidades de los Estados, los cuales, del mismo modo, gozaban de inmunidades absolutas. ${ }^{20}$ En ese sentido, el Acta de las Inmunidades de las Organizaciones Internacionales, codificada por los Estados Unidos de América en 1945, retoma el espíritu de ese momento, disponiendo que "[1]as organizaciones internacionales... gozarán de la misma inmunidad de jurisdicción y ante cualquier forma de proceso judicial de igual forma que los gobiernos extranjeros...". ${ }^{21}$ En Branno $v$ Ministry of War, la Corte Italiana de Casación incluso se refirió a la "soberanía” de la Organización del Tratado del Atlántico Norte (OTAN). ${ }^{22}$

Una de las razones de la tradicional equivalencia entre las inmunidades de las OI y las inmunidades de los Estados puede yacer en el hecho de que las OI no fueron originalmente conceptualizadas como personas jurídicas distintas a los Estados, sino que más bien fueron consideradas como entidades colectivas que representaban a los Estados Miembros. ${ }^{23}$ Por consiguiente, parecía lógico extender las inmunidades de los Estados o de sus diplomáticos a aquellas organizaciones y sus funcionarios. ${ }^{24}$ Particularmente, las primeras leyes sobre inmunidades parecen reflejar esa equivalencia con los Estados como justificación para conceder inmunidades de jurisdicción a las OI. ${ }^{25}$ Así, muchos de los primeros casos relativos al otor-

20 SINGER, "Jurisdictional Immunity of International Organizations" (nota 3) $58-65$.

21 Código 22 de los EUA § 288 a (b) (1994).

22 Branno v Ministry of War, Corte de Casación, Riv. Dir int., 22 ILR 756, 757 (1955).

23 B. FAßBender, "Die Völkerrechtssubjektivität internationaler Organisationen, (1986), en 37 Österreichische Zeitschrift für öffentliches Recht und Völkerrecht 17, 20.

24 Reinisch, International Organizations Before National Courts (nota 15) 259.

25 Similar al Acta de Inmunidades de las Organizaciones Internacionales de los EUA, supra nota 20, el Acta del Reino Unido sobre Privilegios Diplomáticos (Extensión) de 1944 reconoce inmunidad a las OI en la misma medida que a los Estados; Anuario de la Comisión de Derecho Internacional (1977) vol. II Parte Uno, 
gamiento de inmunidades a las OI en cortes nacionales se basaron en la premisa de que las OI eran entes colectivos representando a los Estados, por lo que debían ser tratados como Estados. ${ }^{26}$

Sin embargo, mientras que las inmunidades de los Estados se han limitado cada vez más a los actos de iure imperii, discerniendo los actos soberanos de los actos considerados como de iure gestionis, tal diferenciación no ha sido instaurada con respecto a las OI. A pesar de que un gran número de académicos abordaron la posibilidad de hacer la diferenciación entre actos de comercio y los actos públicos de las OI, ${ }^{27}$ los tribunales nacionales usualmente han vacilado en aplicar esta doctrina. ${ }^{28}$ De hecho, la distinción ha sido

152. En su mensaje del 4 de agosto de 1919, relacionado con la Sociedad de la Naciones, el Consejo Federal de Suiza declaró que es "natural que la Sociedad de las Naciones se beneficie de los mismos privilegios e inmunidades como cualquier Estado con el que [Suiza] mantenga relaciones diplomáticas; citado en P Freymond, "Remarques sur l'immunité de juridiction des organisations internationales en matière immobilière" (1955-6), en 53 Freiedens-Warte 365, 366.

26 ReInisch, International Organizations Before National Courts, (nota 15) 259.

27 N. VALticos, "Les contrats conclus par les organisations internationales avec des personnes privées, Rapport provisoire et projet de résolution - Rapport définitive et projet de résolution" (1977), en Anuario del Instituto de Derecho Internacional 1, 3; Ignaz Seidl-Hohenveldern, "L'immunité de juridiction des Communautés européennes" (1990), en Revue du Marché Commun 475, 151; Henry G. ScherMERs, "International Organizations, Legal Remedies against Acts of Organs" en R. Bernhardt (ed.), Encyclopedia of Public International Law, vol. II (2 ${ }^{\text {a }}$ ed., Norte de Holanda, 1995) 1318, 1318. Cfr. R. Higgins, Problems and Processes: International Law and How We Use It, (1994) 93.

28 La diferencia puede rastrearse a la jurisprudencia de algunos países, en particular a la más reciente de los EUA posterior a la adopción del caso Nokalva, supra nota 14, y en casos anteriores italianos, vid., v. g., Branno v Ministry of War, Corte de Casación, Riv. Dir. Int. (1955), 352, 22 ILR 756; Porru v FAO, 25 de junio de 1969, Corte de primera instancia de Roma (Sala Laboral) [1969] UNJYB 238, FAO v INPDAI, Suprema Corte de Casación, 18 de octubre de 1982 [1982] UNJYB 234, cuyo criterio fue abandonado en FAO v Colagrossi, Corte de Casación, 18 de mayo de 1992, No. 5942, 75 RivDI (1992), 407, donde la Suprema Corte de Italia reconoció la inmunidad de jurisdicción absoluta de la organización internacional demandada. 
ocasionalmente revisada por algunos tribunales, por ejemplo, en el caso League of Arab States v. TM, en donde un juez de apelaciones en Bélgica sostuvo en una controversia laboral que se trataba de un actium iure gestionis, al cual, de conformidad con el derecho internacional consuetudinario, no le correspondía inmunidad alguna. ${ }^{29}$ Consideraciones similares fueron aceptadas por los tribunales rusos en el caso contra la Compañia Internacional Radiodifusora Interestatal "MIR" (International Inter-State Broadcasting Company "MIR"). El que la petición de inmunidad de jurisdicción fue rechazada a dicha OI respecto de determinadas actividades empresariales, ya que éstas fueron consideradas como ajenas a sus fines funcionales. ${ }^{30}$ En el caso Greenpeace Nederland v Euratom, una corte de apelaciones de los Países Bajos fue un paso más allá y rechazó la petición de inmunidad de la Comunidad Europea de la Energía Atómica (EURATOM) después de haber analizado las frecuentes violaciones al orden jurídico nacional cometidas por esa OI, decidiendo que éstas no podrían ser consideradas como parte de la supuesta misión de la organización y que estas no se relacionaban directamente con el cumplimiento de sus propósitos. ${ }^{31}$ Sin embargo, la decisión del tribunal de apelaciones fue revertida por la Suprema Corte de los

29 League of Arab States v TM, Corte de Casación de Bélgica, ILDG 42 (BE 2001). Esta distinción también se evidencia en la jurisprudencia de otros países, en particular los casos estadounidenses más recientes posterior al Caso Nokalva (nota 16); para un caso ruso vid., State Tax Servicev (Anonymous) An International Organization, Decision on 'nadzor review', Corte Suprema Mercantil de Rusia, 18 de enero de 2001, ILDC 26 (RU 2001), para un caso mexicano vid. Instituto Latinoamericano de la Comunicación Educativa, Amparo en Revisión 348/2001, Reg. num. 17498, Novena Época, Semanario Judicial de la Federación y su Gaceta, Tomo XVII, marzo de 2013.

30 State Tax Servicev (Anonymous) An International Organization, Decision on 'Nadzor review' ILDC 26 (RU 2001) (Rusia, Suprema Corte Mercantil, 18 de enero de 2001).

31 El razonamiento de la Corte de Apelación fue explicado en la sentencia de la Suprema Corte, LJN: BA9173, Suprema Corte de los Países Bajos, 01984/07 CW, 13 de noviembre de 2007. 
Países Bajos, la cual se negó a revisar los actos de la OI bajo la presunción de que la EURATOM pudo haber ejecutado sus funciones sin haber cometido las supuestas acciones delictivas. ${ }^{32}$ En general, los tribunales nacionales prefieren evitar hacer distinciones entre actos de iure imperii y actos de iure gestionis. ${ }^{33}$

Por lo tanto, mientras que la doctrina absoluta de las inmunidades de las OI es aún considerada como un argumento válido frente a las cortes nacionales, la misma posición privilegiada de los Estados en relación con sus inmunidades jurisdiccionales ha sido desafiada en la mayoría de los tribunales nacionales como una cuestión de "justicia para los demandantes" ${ }^{34}$ y del "Estado de Derecho". ${ }^{35}$ En particular, tal cuestionamiento se basó en el argumento que las inmunidades absolutas de los Estados conllevan a una denegación de los recursos judiciales de los individuos para la reivindicación de sus derechos contra el Estado en cuestiones contractuales y extracontractuales. ${ }^{36}$ Por tal razón, la doctrina absoluta de las inmunidades de los Estados fue considerada como obsoleta y se ha restringido a los actos de iure imperii.

\section{Ibidem.}

3з Para una serie de ejemplos vid., Maruba S.C.A. Empresa de Navegación Marítima v Itaipú, Corte Suprema de Justicia de la Nación Argentina, S.C.M. 1109 XXIX, 5 de febrero de 1998; Company Baumeister Ing Richard L v. O, Corte Suprema de Austria, ILDC 362 (AT 2004); Prewitt Enterprises Incorporated and Similarly situated purchasers of petroleum products in the United States v. Organization of Petroleum Exporting Countries, Corte de Apelación de los Estados Unidos, 353 F 3d 916 (Onceavo circuito 2003); vid., en general Cedric Ryngaert, "The Immunity of International Organizations before Domestic Courts: Recent Trends" (2010), en 7 International Organizations Law Review 12 1, 126.

34 James Crawford, "International Law and Foreign Sovereigns: Distinguishing Immune Transactions" (1984), en 54 British Yearbook of International Law 75, 77.

35 Hersch Lauterpacht, "The Problem of Jurisdictional Immunities of Foreign States” (1951), en 28 British Year Book of International Law 220, 220.

36 Ibidem. 
Otra diferencia importante entre el marco normativo de la inmunidad de los Estados y el marco normativo de las inmunidades de las OI es que éstas últimas no están sometidas a la jurisdicción obligatoria de un tribunal internacional que pueda compensar la ausencia de jurisdicción por parte de las cortes nacionales por demandas en su contra. Asimismo, mientras que las víctimas de violaciones a los derechos humanos, como norma general, pueden presentar sus reclamos ante los tribunales nacionales del Estado que las ha perpetrado, tales recursos "nacionales" difícilmente están disponibles dentro de las OI. A lo sumo, dichos mecanismos de solución de controversias existen, generalmente, en una fase incipiente, si es que se encuentran disponibles del todo. ${ }^{37}$ Del mismo modo, dado que ninguna OI es aún Parte de un tratado internacional en materia de derechos humanos, ${ }^{38}$ podría estar abierto a debate si las OI están obligadas a garantizar el derecho a un recurso jurídico y el derecho de acceso a los tribunales de los individuos y otras entidades privadas en caso de que les sean conculcados sus derechos humanos. A pesar de que en la actualidad existe un consenso generalizado de que las OI deben respetar los derechos humanos más fundamentales, ${ }^{39}$ es aún controvertido cuáles derechos humanos recaen en este

37 Éstos se limitan a tribunales administrativos competentes para dirimir controversias laborales entre una OI y miembros de su personal; vid., Sección IV.

${ }^{38}$ Sin embargo, vid., para los procedimientos de adhesión de la Unión Europea (UE) al Convenio Europeo de Derechos Humanos el Reporte Final para el Comité Directivo para los Derechos Humanos (CDDH), Quinta negociación entre el grupo ad hoc de negociación de la CDDH y la Comisión Europea sobre la adhesión de la UE al Convenio Europeo de Derechos Humanos, 47+1(2013)008rev2, 10 de junio de 2013, Consejo de Europa.

39 Tal conclusión también se deriva de los Artículos de Responsabilidad de las Organizaciones Internacionales, elaborados por la Comisión de Derecho Internacional y adoptados por la Asamblea General de la ONU en 2012, que estipulan en su Artículo 53 que las contramedidas tomadas por una OI en contra de otra 
ámbito y cuál es su fundamento legal. En ese sentido, la doctrina discute sobre si las obligaciones de las OI de respetar y garantizar los derechos humanos derivan de las obligaciones convencionales de sus Estados miembros, ${ }^{40}$ de los principios generales del derecho, ${ }^{41}$ de la costumbre internacional, ${ }^{42}$ o del hecho mismo de que los Estados ejercen sus poderes soberanos. ${ }^{43}$ Además, algunos instrumentos internacionales, como la Convención sobre Prerrogativas e Inmunidades de las Naciones Unidas, ${ }^{44}$ requieren expresamente que la Organización establezca los medios apropiados para la solución de controversias que deriven de disputas de carácter privado en las que

OI no afectarán las obligaciones de la primera de proteger los derechos humanos; 'Draft Articles on the Responsibility of International Organizations' Reporte de la Comisión de Derecho Internacional, 63 sesión, UN Doc. A/66/10 (3 de mayo de 2011).

40 Tawhida Ahmed e Israel de Jesús Butler, 'The European Union and Human Rights: An International Law Perspective' (2006) 17 European Fournal of International Law 771, 801-835.

41 Bruno Simma y Philip Alston, "The Sources of Human Rights Law: Custom, Jus Cogens, and General Principles" (1988), en 12 Australian Year Book of International Law 82, 82-108. Para las primeras discusiones sobre el estatus del derecho a un recurso efectivo como un principio general del derecho en el sentido del Artículo 38 del Estatuto de la Corte Internacional de Justicia, al menos en lo que corresponde a los derechos de los empleados de una OI en contra de ésta en su calidad de patrón, vid., S BASTID, "Have the UN Administrative Tribunals Contributed to the Development of International Law?" en W Friedmann et al., (eds.), Transnational Law in a Changing Society: Essays in Honor of Philip C. Fessup (Nueva York, Columbia University Press, 1972) 309.

42 Alexander Orakhelashvili, "The Acts of the Security Council: Meaning and Standards of Review" (2007) 11 Max Planck Yearbook of United Nations Law 143, 177.

${ }^{43}$ Robert MaCorquodale, "International Organisations and International Human Rights Law: One Giant Leap for Humankin" en K. H. KaIKobad у M Bohlander (eds.), International Law and Power: Perspectives on Legal Order and Fustice, Essays in Honour of Colin Warbrick (Leiden; Boston, Martinus Nijhoff Publishers, 2009) 141, 141-162.

${ }^{44}$ Convención de Inmunidades de la ONU (nota 5). 
la ONU sea parte. ${ }^{45}$ Por consiguiente, la Convención claramente establece el deber de proporcionar procedimientos alternativos de solución de controversias, los cuales mitigarían el reconocimiento de inmunidades por parte de las cortes nacionales. ${ }^{46}$

\section{Funciones CRECiEntes}

La pretensión de las OI que se respeten sus inmunidades jurisdiccionales absolutas ha sido una constante ante las cortes nacionales. Del mismo modo, las OI han sido consistentemente reticentes a someterse a mecanismos alternativos de solución de controversias. Al mismo tiempo, las OI han incrementado en número y tamaño, y han expandido sus actividades y sus ámbitos de actuación. Éstas regulan cada vez más una amplia gama de asuntos que anteriormente eran del dominio exclusivo de los Estados. En particular, después de la caída del Muro de Berlín y el fin de la era de la Guerra Fría, las OI comenzaron a ejecutar más actos de autoridad. ${ }^{47}$ De esta forma, las OI influencian la política nacional y los procesos legales, y limitan cada vez más la esfera de acción de los gobiernos nacionales. Mientras que el objeto de regulación de las OI está en expansión, es cada vez menos necesario el consentimiento estatal para que las normas internacionales se vuelvan vinculantes para los Estados. ${ }^{48} \mathrm{Al}$ mismo tiempo, las OI confían en el axioma del derecho internacional que señala que los ordenamientos jurídicos nacionales, incluyendo las normas constitucionales, en principio, no pueden servir de justificación para el incumplimiento de las normas jurídicas internacionales. ${ }^{49} \mathrm{De}$ mayor consideración es el hecho de que los actos de las OI no se

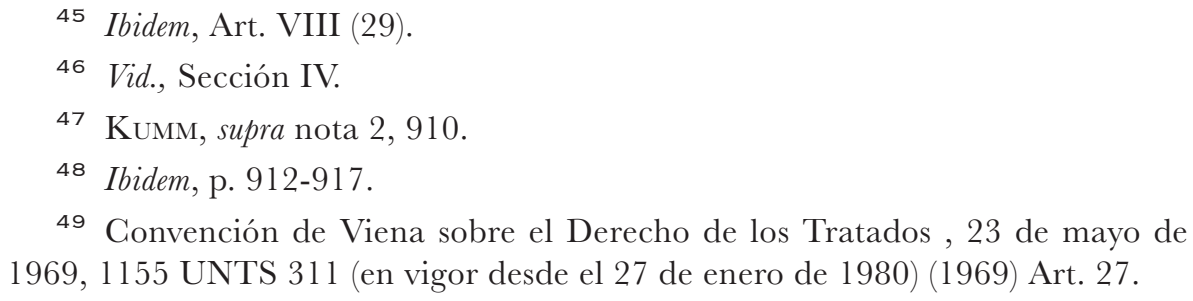

49 Convención de Viena sobre el Derecho de los Tratados , 23 de mayo de 1969, 1155 UNTS 311 (en vigor desde el 27 de enero de 1980) (1969) Art. 27. 
dirigen primordialmente a los Estados, sino que cada vez más se dirigen a otros actores, incluyendo a los individuos. Con estos amplios poderes que les son encomendados a las OI, las situaciones en que el ejercicio de su autoridad puede afectar negativamente a los individuos han incrementado. Los ejemplos más paradigmáticos incluyen la falta de protección jurídica para los individuos en relación con las sanciones selectivas del Consejo de Seguridad de la ONU (CS o CSNU), ${ }^{50}$ las decisiones y acciones de otras entidades y agencias de la ONU (como la Misión de Administración Provisional de la ONU en Kosovo -MINUK - y el Alto Representante de la ONU para Bosnia y Herzegovina), ${ }^{51}$ y las acciones de las Fuerzas de Kosovo (KFOR), las fuerzas operativas para el mantenimiento de la paz dirigidas por la OTAN en ese país. ${ }^{52}$ De este modo, las OI amplían sus competencias y funciones, ejerciendo cada vez más actos de autoridad a nivel internacional $^{53} \mathrm{y}$, al mismo tiempo, insisten en la doctrina absoluta de las inmunidades jurisdiccionales y de ejecución ante los tribunales de los Estados nacionales. Sostengo que, al hacer esto, las OI amplían correspondientemente sus pretensiones de inmunidad.

50 Glemens A Feinäugle, "The UN Security Council Al-Quaida and Taliban Sanctions Committee: Emerging Principles of International Institutional Law for the Protection of Individuals" (2008), en 9 German Law fournal 1513, 1539. Sobre las respuestas nacionales al régimen de sanciones del Consejo de Seguridad de la ONU, vid., el capítulo 3 (Veronika Fikfak) en M. Kanetake y A. Nollkaemper, (eds.) The Rule of Law at the National and International Levels: Contestations and Deference (Hart Publishing, Oxford).

51 Richard Caplan, "Who Guards the Guardians? International Accountability in Bosnia" (2005), en 12 International Peacekeeping 463.

52 John Gerone, "Minding the Gap: Outlining KFOR Accountability in Post-Conflict Kosovo" (2001), en 12 European Fournal of International Law 469.

53 von Bogdandy, Dann y Goldmann, "Developing the Publicness of Public International Law: Towards a Legal Framework for Global Governance Activities" (nota 12) 1376-1400. 


\section{El papel del argumento de la necesidad funcional}

Legalmente, la ampliación de las pretensiones de inmunidad por parte de las OI podría ser visto como resultado del concepto de la personalidad funcional, según el cual las OI gozan de personalidad jurídica internacional en la medida necesaria para realizar sus funciones. De este modo, en términos legales, las OI no pueden actuar más allá de su personalidad funcional. Cualquier acto que no esté cubierto por dicha personalidad es considerado como ultra vires. ${ }^{54}$ Mientras tengan esta personalidad funcional, las OI gozan también de inmunidad funcional, la cual cubriría todos los actos que se ejecuten en el ejercicio de sus funciones. Dado que las OI sólo pueden actuar dentro del ámbito de su personalidad funcional -siguiendo la lógica de este argumento-, no quedaría espacio alguno para actos no cubiertos por la inmunidad. Tal visión necesariamente conlleva a la exigencia de inmunidades absolutas para las OI. ${ }^{55}$ Bajo esta interpretación, la necesidad funcional difícilmente puede jugar un papel relevante para delimitar las inmunidades de las OI. Más bien, permite que las inmunidades de jurisdicción le sean concedidas a las OI en cualquier circunstancia, ya que siempre se considerará que las OI actúan dentro del ámbito de sus funciones. ${ }^{56}$

54 Certain Expenses of the United Nations (Article 17, Paragraph 2, of the Charter) [1962] ICJ Reports 151 (Opinión Consultiva de 20 de julio 1962), 168.

55 August Reinisch y Ulf Andreas Weber, "In the Shadow of Waite and Kennedy: The Jurisdictional Immunity of International Organizations, The Individual's Right of Access to the Courts and Administrative Tribunals as Alternative Means of Dispute Settlement" (2004), en 1 International Organizations Law Review 59, 63 (citando a Seidl-Hohenveldern en un artículo sin publicarse del Comité de Inmunidades Jurisdiccionales de los Estados de la Asociación de Derecho Internacional (ILA, por sus siglas en inglés), referido en el Reporte Final de Inmunidad de los Estados, ILA Conferencia de Buenos Aires 1994, p. 475).

56 Emmanuel Gaillard e Isabelle Pingel-Lenuzza, "International Organisations and Immunity from Jurisdiction: to Restrict or to Bypass" (2002) 51 International and Comparative Law Quarterly 1, 10. 
ili. Contestaciones de los tribunales nacionales

1. Revisando la compatibilidad de las inMUNidAdes CON LOS DERECHOS HUMANOS

Mientras que fueron esporádicos los casos en que las cortes nacionales negaron las inmunidades a las OI bajo el argumento de que los actos impugnados no eran de iure imperii, otra serie de decisiones judiciales nacionales han objetado la regla tradicional de inmunidades absolutas de las OI. Esta nueva tendencia se refiere a la práctica de algunos jueces locales quienes condicionaron el reconocimiento de inmunidades a una OI al cumplimiento de ciertos estándares de derechos humanos por parte de esas organizaciones. De esto se desprende que, en casos de que una demanda sea presentada contra una OI por supuestas violaciones a los derechos humanos, los tribunales nacionales se abstendrían de revisar tales actos si existen mecanismos a los que las víctimas pudieren recurrir.

Antes de analizar algunas de estas decisiones judiciales, es necesario contextualizar su desarrollo. Primero, debe señalarse que el aumento de esta práctica se correlaciona con la ampliación de los poderes de las OI explicado en las secciones anteriores, y puede considerarse como un cuestionamiento de los Estados a la legitimidad de la autoridad ejercida por las OI sobre los individuos y otras entidades privadas. Al mismo tiempo, esta tendencia también puede ser vista como parte del desarrollo de los derechos humanos, en particular del derecho de acceso a los tribunales y del derecho a un recurso jurídico. Así, la privación del derecho de acceso a los tribunales para determinar los derechos y obligaciones civiles de un individuo plantea dificultades en materia de derechos humanos en el plano internacional, así como serios problemas constitucionales en muchos sistemas jurídicos. ${ }^{57}$ De este modo, está surgiendo un

57 Mauro Cappelletti, The Fudicial Process in Comparative Perspective (Claredon Press, 1989); Karl Heinz Schwab y Peter Gottwald, "Verfassung und 
consenso por parte de los Estados, el cual se refleja en los instrumentos internacionales de derechos humanos, donde el derecho de acceso a los tribunales y el derecho a un recurso efectivo pueden ser considerados como fundamentales. Éstos son reconocidos, inter alia, en los Artículos 8 y 10 de la Declaración Universal de Derechos Humanos de $1948,{ }^{58}$ en los Artículos 2 (3) y 14 (1) del Pacto Internacional de Derechos Civiles y Políticos, ${ }^{59}$ en los Artículos 6 y 13 del Convenio Europeo de Derechos Humanos, ${ }^{60}$ y en los Artículo

Zivilprozess" en W. J. HABscheID (ed.), Effektiver Rechtsschutz und verfassungsmässige Ordnung (Bielefeld, Gieseking-Verlag, 1983) 1; Reinisch, International Organizations Before National Courts (nota 15) 290-313.

58 Resolución de la Asamblea General de la ONU 217 A (III), UN Doc. A/810 (1948), 71; la interpretación del artículo sobre las garantías judiciales como parte del derecho de acceso a la justicia sigue, inter alia, el proyecto de texto del artículo, el cual originalmente disponía que "[t] oda persona tendrá acceso a tribunales independientes e imparciales en la sustanciación de cualquier acusación penal formulada contra ella, y de sus derechos y obligaciones"; Reporte de la Comisión de Derechos Humanos de la ONU, ECOSOC Official Records, $3^{\text {er }}$ año, 6 a Sesión, E/600, Anexo A.

59 UN Treaty Series, Vol. 999, 171; para la interpretación del artículo sobre las garantías judiciales en las que se garantiza el derecho de acceso a los tribunales vid., también el Comentario General No. 13 del Comité de ONU de Derechos Humanos, el cual conceptualiza el acceso a los tribunales como parte inherente de los derechos otorgados en el Art. 14 del Pacto, al referirse a la "equidad ante las cortes, incluyendo el acceso igualitario a los tribunales"; Comentario General No. 13: Equality before the courts and the right to a fair and public hearing by an independent court established by law, 13 de abril de 1984, párr. 3, disponible en: <http://www.unhchr.ch/tbs/doc.nsf/0/ bb722416a295f264c12563ed0049dfbd>, (último acceso en febrero 2013).

60 Convenio para la Protección de los Derechos Humanos y las Libertades Fundamentales, 4 de noviembre de 1950, ETS 5, 213 UNTS 221 (1950). La interpretación del Art. 6(1) de la Comisión Europea de Derechos Humanos garantizando el derecho de acceso a los tribunales ha sido adoptada en diversas sentencias, incluyendo: App No 4451/70 Golder v the United Kingdom Ser A18 (TEDH, Sentencia de 21 de febrero de 1975), párr. 36; App No 23452/94 Osman v the United Kingdom ECHR 1998-VIII (TEDH, Pleno, Sentencia de 28 de octubre de 1998), párr. 136. 
8 y 25 de la Convención Americana sobre Derechos Humanos; ${ }^{61}$ el derecho a que el caso de un individuo sea conocido también está garantizado bajo el artículo 7 de la Carta Africana sobre los Derechos Humanos y de los Pueblos. ${ }^{62}$ El derecho de acceso a los tribunales y el derecho a un recurso efectivo derivan también de las reglas tradicionales que prohíben la denegación de justicia, las cuales han sido definidas a través de una amplia serie de decisiones arbitrales en el contexto del otorgamiento de los derechos mínimos sobre el tratamiento de los extranjeros. ${ }^{63}$ Consecuentemente, estos derechos son considerados como parte de la costumbre internacional. ${ }^{64}$

A pesar del desarrollo de estos derechos, las inmunidades jurisdiccionales no han sido afectadas por la adopción de instrumentos de derechos humanos. De este modo, en lo que respecta a la inmunidad de los Estados, la Corte Internacional de Justicia (CIJ), en el caso sobre las Inmunidades Furisdiccionales del Estado, ${ }^{65}$ decidió que actualmente la costumbre internacional establece que un Estado no puede ser privado de su inmunidad aun cuando se presuma que cometió serias violaciones al derecho internacional de

61 Convención Americana sobre Derechos Humanos, 22 de noviembre de 1969, 1144 UNTS 123, OAS Treaty Series No. 36 (1969).

62 Carta Africana sobre los Derechos Humanos y de los Pueblos, 1520 UNTS 217.

63 Vid., v. g., Restatement (Third) of the Foreign Relations Law of the United States (1986) $§ 711$.

64 En el caso Rubio v the Universal Postal Union, el Tribunal Administrativo de la Organización Internacional del Trabajo también observó que la negativa de dirimir este caso constituiría una denegación al debido proceso y sería contrario a los principios generales, la Declaración Universal de los Derechos Humanos y a la Convención Americana sobre Derechos Humanos de 22 de noviembre de 1969; ILOAT, 10 de julio de 1997, Sentencia No. 1644, párr. 12, citado en A Reinisch, 'Privileges and Immunities,' en J Klabbers y A Wallendahl (eds.), Research Handbook on the Law of International Organizations, Edward Elgar Publishing Ltd (2011) 132-156, 151.

65 Furisdictional Immunities of the State (Germany v Italy : Greece intervening) [2012] ICJ Reports 99 (3 de febrero de 2012). 
los derechos humanos o al derecho internacional humanitario. En esta sentencia, la CIJ, basándose en las conclusiones del Tribunal Europeo de Derechos Humanos (TEDH) en los casos de Al-Adsani ${ }^{6}{ }^{6}$ y Kalogeropoulou, ${ }^{67}$ no aceptó la proposición de que el derecho internacional permite a los tribunales de un Estado negar la inmunidad de otro Estado en lo que atañe a la responsabilidad civil por violaciones graves a los derechos humanos. ${ }^{68}$ Ambos tribunales, la CIJ y el TEDH, fundamentaron sus decisiones haciendo referencia al Reporte de Inmunidades Jurisdiccionales de los Estados y sus Propiedades, preparado por el Grupo de Trabajo de la Comisión de Derecho Internacional (CDI). ${ }^{69}$ En dicho reporte, la CDI señaló que uno de los argumentos que con creciente frecuencia había sido planteado ante las cortes nacionales consistía en que la inmunidad de los Estados debía ser denegada en casos de homicidio o lesiones que resultaren de la ejecución de actos soberanos en contravención a las normas de derechos humanos con el rango de jus cogens, en particular la prohibición de la tortura. Sin embargo, la CDI concluyó que, mientras que en algunos casos se mostraba cierta empatía por dicho argumento, en muchas de las sentencias nacionales los Estados habían tenido éxito al invocar su inmunidad soberana. ${ }^{70}$

A pesar de que la CDI no aceptó la mencionada excepción a la inmunidad soberana, es debatible en qué medida estas conclusiones relativas a las inmunidades de los Estados puedan ser aplicadas a las inmunidades de las OI. Por ello, la creciente autoridad de las

66 App No 35763/97 Al-Adsani v the United Kingdom ECHR 2001-XI (TEDH, 21 de noviembre de 2001).

67 App No 59021/00 Kalogeropoulou and Others v Greece and Germany ECHR 2002-X (TEDH, Sentencia de 12 de diciembre de 2002).

68 Caso de las Inmunidades Jurisdiccionales del Estado (nota 65) 139.

69 En 2004, la Asamblea General de ONU adoptó la parte relevante del Reporte como la Convención de Inmunidades Jurisdiccionales de los Estados y sus Propiedades; GA Official Records, 59 Sesión, Sup. No. 49 (A/59/49).

70 Vid., Anexo al Reporte de la Comisión de Derecho Internacional en los trabajos de sus $51^{\circ}$ Sesión, A/54/10, párrs. 6 y 7. 
OI vis-à-vis los individuos y las entidades privadas, sus virtualmente absolutas inmunidades ante los tribunales nacionales y su renuencia a someterse a mecanismos alternativos de solución de controversias han llevado a los jueces y a los académicos a responder a las pretensiones de las OI de ampliar el ámbito de sus inmunidades. De este modo, surgió la idea de restringir dicha inmunidad al exigir protección alternativa.

2. El REQuisito de protección alternativa en La JURISPRUDENCIA SOLANGE

En esencia, la idea de requerir protección alternativa asegura que los tribunales nacionales se abstendrán de revisar los actos de una OI sólo si dicha organización cuenta con un mecanismo para revisar y controlar las violaciones a los derechos humanos, que otorgue una protección efectiva alternativa a la de las cortes nacionales. Este requisito ha sido considerado obligatorio para el Estado foro, evitando de ese modo la cuestión de si una OI está obligada a respetar los derechos humanos en general, y el derecho de acceso a los tribunales y el derecho a un recurso jurídico en particular.

Inicialmente, este requisito fue concebido en el contexto del control judicial de los derechos fundamentales llevado a cabo por las autoridades de un Estado que había implementado los actos de una OI. Este control jurisdiccional fue solicitado incidentalmente en un proceso legal en el cual las OI no fueron partes del litigio. Si el requisito se entiende como una respuesta a los poderes crecientes de las OI, no es coincidencia que esta oposición fuera dirigida en contra de una organización supranacional, la Comunidad Europea (CE), de las primeras en extender sus poderes y competencias de manera que incidía en los derechos humanos. Así, el requisito de un foro alternativo y efectivo que fuere capaz de proteger los derechos humanos fue originalmente concebido por la Corte Constitucional de Alemania en su 
decisión conocida como Solange I de $1974,{ }^{71}$ en la cual la Corte aceptó controlar jurisdiccionalmente los actos de la CE "siempre y cuando"* el derecho Comunitario no ofreciera una protección alternativa comparable a la que otorgaba la Constitución alemana. ${ }^{72}$ En su posterior decisión de 1986, en la sentencia Solange II, ${ }^{73}$ la Corte Constitucional alemana revisó nuevamente los estándares de protección de los derechos humanos otorgados por la $\mathrm{CE}$ y determinó, por el contrario, que la organización había desarrollado un nivel de protección de derechos humanos igual al establecido en la Ley Fundamental alemana, incluyendo los recursos disponibles ante el Tribunal Europeo de Justicia (TEJ). Tal y como fue estipulado por el dicho tribunal, las normas procesales del TEJ satisfacían los requerimientos de debido proceso de un Estado respetuoso del Estado Derecho, incluyendo el derecho de audiencia. De este modo, la Corte Constitucional alemana justificó su abstención de revisar los actos de los órganos de la GE "siempre y cuando" esa protección equivalente fuera garantizada por esa OI. La jurisprudencia Solange fue más o menos adoptada de manera expresa por otros tribunales nacionales, siendo la Corte Constitucional italiana la más prominente de éstas, ya que constantemente sostuvo, desde su decisión de 1973 en el caso Frontini, que los actos de la CE no pueden derogar determinados principios fundamentales o derechos

71 Internationale Handelsgesellschaft v Einfuhr-und Vorratstelle für Getreide und Futtermittel [1974] CMLR 540 (Alemania, Corte Constitucional Federal, 29 de mayo de 1974.

* Es de notarse la relación entre el término alemán "solange" con su traducción al inglés "as long as", i.e., siempre y cuando, mientras que, en tanto que, siempre que. [N.T.]

72 Vid., también A. Haratsch, Die Solange-Rechtsprechung des Europäischen Gerichtshofs für Menschenrechte (2006) ZaöRV 66, 927-947 y REINISCH y Weber, "In the Shadow of Waite and Kennedy: The Jurisdictional Immunity of International Organizations, The Individual's Right of Access to the Courts and Administrative Tribunals as Alternative Means of Dispute Settlement" (nota 55) 74.

73 In re application of Wünsche Handelsgesellschaft, Federal Constitutional Court, [1987] 3 CMLR 225 (Alemania, Corte Constitucional Federal). 
inalienables de las personas. ${ }^{74}$ Esos principios fundamentales y derechos inalienables son contrapesos las limitaciones de la soberanía que los Estados aceptan en razón de su membresía en una OI. Por ende, cuando las instituciones de un Estado ejercen funciones soberanas, deben respetar los valores fundamentales y los principios de la Constitución; la atribución de poderes a las instituciones europeas no implica una renuncia total a dichos valores y principios. ${ }^{75}$ En una etapa posterior, el requerimiento de protección alternativa fue desarrollado por los tribunales nacionales en casos presentados en contra de las OI, en los que se invocó el respeto de sus inmunidades.

3. El requisito de una protección alternativa en casos DE INMUNIDADES JURISDICCIONALES

Después de las decisiones Solange, la Corte Constitucional de Alemania estaba preparada para examinar el requerimiento de protección alternativa de los derechos humanos en casos presentados en contra de otras OI, como la Organización Europea para la Seguridad de la Navegación Aérea (EUROCONTROL) ${ }^{76}$ y la Oficina Europea de Patentes $(\mathrm{OEP}),{ }^{77}$ las cuales invocaron sus inmunidades jurisdiccio-

74 Frontiniv Ministero Delle Finanze, caso 183/73, Corte Constitucional de Italia, sentencia de 27 de diciembre de 1973, traducida en [1974] 2 CMLR 386,387.

75 ARMin VON BOGDANDy, "The European Union as a human rights organization? Human rights and the core of the European Union" (2000), en 37 Common Market Law Review 1307; Paul Craig y Gráinne De Búrca, The Evolution of EU Law (1 ${ }^{\circ}$ ed., Oxford, Oxford University Press, 1999) 201-205; Henry G. Schermers y Denis F. Waelbroeck, Fudicial Protection in the European Union (Kluwer Law International, 2001).

76 Hetzel v EUROCONTROL, Corte Constitucional Federal, Segunda Sala, 10 de noviembre de 1981, 2 BvR 1058/79, BVerG, 63.

77 Corte Constitucional Federal, 4 de abril de 2001, 2 BvR 2368/99, NJW 2001, 2705; vid., también Brunner et. al. v The European Union Treaty (Constitutionality of the Maastricht Treaty), Corte Constitucional Federal de Alemania, 12 de octubre de 1994, Common Market Law Review (1994), 251, y Reinisch, Weber, supra nota 55, 74 . 
nales ante las cortes alemanas. En el caso de EUROCONTROL, la Corte Constitucional reconoció la inmunidad de dicha organización después de que determinó que el Tribunal Administrativo de la Organización Internacional del Trabajo (OIT) era competente para pronunciarse sobre una demanda laboral entre ese organismo y el afectado, estableciendo que el Tribunal era un recurso alternativo adecuado para el asunto en cuestión. Tal y como se indicó en la sentencia, el reconocimiento de inmunidades ante las cortes alemanas no violaba los requerimientos mínimos de la Constitución alemana. ${ }^{78}$ De igual manera, la Suprema Corte de Suiza describió la obligación de proporcionar mecanismos alternativos de solución de controversias como la "contrapartida" a las inmunidades que gozan las organizaciones internacionales. ${ }^{79}$ También, las cortes norteamericanas aceptaron que la concesión de inmunidades a las OI puede entrar en conflicto con las exigencias constitucionales de proporcionar al demandante un foro para la solución de controversias. Así, en el caso Weiner, ${ }^{80}$ una corte penal de la ciudad de Nueva York trató encontrar el equilibrio entre la inmunidad de la ONU y el derecho constitucional de los ciudadanos norteamericanos de acceso a los tribunales. En el mismo sentido, una corte de apelaciones del Distrito de Columbia (D.C.) subrayó en Urban v. the

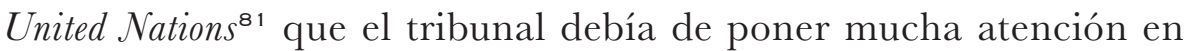

78 Ibidem, párr. 22: 'Dementsprechend hat das Bundesverfassungsgericht festgestellt, dass Status und Verfahrensgrundsätze des ILOAT sowohl dem internationalen Mindeststandard elementarer Verfahrensgerechtigkeit als auch den rechtsstaatlichen Mindestanforderungen des Grundgesetzes genügen [...]. Vor diesem Hintergrund legen die Beschwerdeführer nicht substantiiert dar, dass ein strukturelles Rechtsschutzdefizit bestünde, dessen sich die für die auswärtigen Angelegenheiten zuständigen Bundesorgane annehmen müssten' (énfasis añadido).

79 Groupement d'Entreprises Fougerolle et consorts v CERN, Primera Corte Civil del Tribunal Federal de Suiza, 21 de diciembre de 1992, ATF 118 Ib 562.

80 People v Mark S. Weiner, 378 N.Y.S.2d 966, Corte penal de la Ciudad de Nueva York, 19 de enero de 1976 [1976] UNJYB 249.

81 Urban v the United Nations, 768 F.2d 1497, 1500 (D.C.Cir 1985). 
no menoscabar el derecho constitucional de un individuo de acceso a los tribunales. Igualmente, los tribunales italianos desarrollaron un enfoque restrictivo para el otorgamiento de inmunidades a las OI en casos como FAO v. INPDAI. ${ }^{82}$

Ciertamente, muchos de los tribunales nacionales respetaron las inmunidades de las OI después de haber revisado, con mayor o menor escrutinio, la efectividad de los recursos alternativos que las organizaciones brindaban a los demandantes. Sin embargo, existen otros ejemplos en los que un tribunal nacional no reconoció las inmunidades a una OI y permitió iniciar procedimientos legales en su contra. En UNESCO v. Boulois, ${ }^{83}$ una corte francesa de apelaciones rechazó la petición de inmunidad después de haber establecido que el reconocimiento de ésta conllevaría inevitablemente a que los individuos no pudieran presentar su caso ante la corte. De acuerdo con el tribunal francés, tal situación sería contraria al orden público, ya que constituiría una denegación de justicia y una violación al Convenio Europeo de Derechos Humanos. ${ }^{84}$ Después de que el requisito de protección alternativa fue respaldado por las instituciones internacionales y por el TEDH, este tipo de resoluciones se hicieron más comunes, particularmente entre los Estados Parte del Convenio Europeo. En un gran número de casos, el Convenio ha sido directamente invocado, como en Siegler v. Western European Union, donde un tribunal de apelaciones de Bélgica negó la inmu-

82 FAO v INPDAI, Suprema Corte de Casación, 18 de octubre de 1982 [1982] UNJYB 234, 235; vid., también FAO v Colagrossi, Corte de Casación, 18 de mayo de 1992, No. 5942 [1992] RivDI 407; para más ejemplos vid., A Reinisch, The Privileges and Immunities of International Organizations in Domestic Courts, OUP, 2013.

83 UNESCO v Boulois, Tribunal de grande instancia de Paris (ord. Rèf.), 20 de octubre de 1997, Rev. Arb. (1997) 575; Corte de apelaciones de París (14e Ch. A) 19 de junio de 1998, XXIV a Yearbook Commercial Arbitration (1999) 294; Rev. Arb (1999) 343 .

84 Sobre el desarrollo de la jurisprudencia relevante en Francia, vid., August Reinisch, "Privileges and Immunities" en J. Klabbers y A. Wallendahl (eds.), Research Handbook on the Law of International Organizations (Cheltenham; Northampton, MA, Edward Elgar, 2011 ) 144, 144-145. 
nidad a esa OI al sostener que cualquier limitación al derecho de acceso a los tribunales no puede restringir el derecho

[...]de una manera o a tal grado que se vea afectada la esencia misma del derecho y que otra limitación semejante no estaría de conformidad con [lo estipulado en el artículo] 6\$1, en el sentido de que éste tiende a perseguir un objetivo legítimo y a que exista una relación de proporcionalidad entre los medios empleados y la finalidad perseguida. ${ }^{85}$

Por ende, la aceptación gradual en el derecho internacional de una inmunidad restringida para las OI proporciona a los tribunales nacionales un argumento jurídico adicional ${ }^{86}$ para su cuestionamiento, lo que a su vez alienta a los jueces locales a revisar el cumplimiento con los derechos humanos y el Estado de Derecho por parte de las OI.

\section{Recepción en el DeREcho internacional}

1. RECEPCIÓN POR PARTE DE LOS TRIBUNALES INTERNACIONALES

En el ámbito internacional, la preocupación por los derechos humanos se reflejó de manera inicial en una serie de disposiciones convencionales que establecen la obligación de las OI de renunciar a su inmunidad cuando ésta implique una denegación de justicia. ${ }^{87}$

85 Sieglerv WEU, Corte de Apelaciones en materia laboral de Bruselas, Sentencia de 17 de setiembre de 2004, fournal des Tribunaux 2004, 617, ILDC 53 (BE 2003).

86 Sobre los tribunales internacionales como "legisladores" vid., también Armin von Bogdandy e Ingo Venzke, In wessen Namen? Internationale Gerichte in Zeiten globalen Regierens (Berlín, Suhrkamp, 2014).

87 Vid., v. g., Art. IV (1) (a), Anexo 1 de la Convención para el Establecimiento de la Agencia Espacial Europea, París, 30 de mayo de 1975, 14 ILM (1975), 855, disponible en: <http://www.esa.int/esapub/sp/sp1300/sp1300EN1.pdf>, (último acceso febrero 2013); vid., también Art. V, Sección 20, donde la obligación de 
De este modo, las decisiones de algunos páneles arbitrales preceden a algunas de las sentencias más conocidas de los tribunales nacionales, en el sentido de que esos páneles buscaban proteger el derecho de acceso a la justicia de un particular, interpretando que la inmunidad de jurisdicción implica el deber de someter una controversia a arbitraje. ${ }^{88}$

No sorprende que posteriormente hayan sido los órganos de derechos humanos quienes tomaron la delantera y desarrollaron el argumento de que las OI deben de proveer foros alternativos a los tribunales nacionales para la protección de los derechos humanos. Dicho argumento fue acogido por primera vez por la Comisión Europea de Derechos Humanos. En M. E Co. v. the Federal Republic of Germany, ${ }^{89}$ la Comisión comenzó observando que el Convenio Europeo de Derechos Humanos no prohíbe a un Estado Parte transferir poderes soberanos a las OI. Sin embargo, la Comisión sostuvo que si un Estado acepta las obligaciones que emanan del Convenio y, posteriormente, concluye otro tratado internacional que inhabilita al Estado mismo de cumplir con sus obligaciones bajo el Convenio, el Estado sería responsable de cualquier violación bajo el primer tratado. Tal y como lo expresó la Comisión, "una transferencia de poderes [a una organización internacional] no necesariamente excluye la responsabilidad de un Estado bajo el Convenio respecto del ejercicio de los poderes transferidos. En caso contrario, las garantías del Convenio podrían ser limitadas o excluidas arbitrariamente

renunciar a la inmunidad está definida respecto de los funcionarios de la ONU, en caso de que las inmunidades "impidan el curso de la justicia".

88 Para uno de los primeros ejemplos vid., $A$ (organisation internationale) v $B$ (société), ICG Arbitration Award, 14 de mayo de 1972, Caso No. 2091, Revue de l'Arbitrage (1975) 252, en el que el panel sostuvo: "La inmunidad de jurisdicción acordada a una OI que carece de jurisdicciones propias la obliga a recurrir a arbitrar los litigios que deriven de sus actividades".

89 App no 13258/87 M \& Co v the Federal Republic of Germany (1990) 64 DR 138 (Comisión Europea de Derechos Humanos, 9 de febrero de 1990). 
y por ende, desprovistas de su carácter imperativo". ${ }^{90} \mathrm{Al}$ final, la Comisión declaró inadmisible la petición contra el acto de la $\mathrm{CE}$, sin embargo, lo hizo después de haber encontrado que la CE contaba con un sistema suficientemente lo desarrollado para la protección de los derechos humanos, incluyendo los recursos ante el TEJ. El requisito de protección alternativa fue posteriormente adoptado en Heinz v. Contracting Parties who are also Parties to the European Patent Convention, ${ }^{91}$ en el que la Comisión expresamente analizó la disponibilidad de un método alternativo de solución de controversias el cual incluía distintas garantías procesales, las cuales satisfacían el análisis de la Comisión sobre la protección equivalente de los derechos humanos dentro de dicha organización.

La necesidad de un foro alterno dentro de las OI fue reafirmado después por el TEDH, cuando en 1999 emitió tres decisiones históricas. En el caso Matthews, ${ }^{92}$ el Tribunal de Estrasburgo aseveró que el Convenio Europeo no impide la transferencia de competencias soberanas a las OI siempre y cuando los derechos humanos, tal y como se estipulan en el Convenio, continúen siendo garantizados por los Estados Parte. Así, los Estados seguían siendo responsables por el respeto de los derechos del Convenio aún después de haber efectuado efectuado tal transferencia. En Matthews, debido a que el TEDH estableció que al demandante no le quedaba recurso alguno para recurrir la legalidad del acto de la CE, esto es ni ante los tribunales nacionales ni ante el TEJ, se declaró la violación al Convenio. Este análisis dio lugar a un concepto restrictivo de las

90 Ibidem.

91 App No 12090/92 Heinzv Contracting Parties who are also Parties to the European Patent Convention (1994) 76-A DR 125 (Comisión Europea de Derechos Humanos, 10 de enero de 1994).

92 App No 24833/94 Matthews v the United Kingdom ECHR 1999-I (TEDH, Pleno, sentencia de 18 de febrero de 1999). 
inmunidades de las OI en los casos de Waite y Kennedy ${ }^{93}$ y Beer $y$ Regan. ${ }^{94}$ En dichas sentencias, el TEDH determinó que el reconocimiento de inmunidades a una OI puede infringir los derechos de los individuos de acceso a los tribunales, a menos que dicha situación sea solventada a través de la disponibilidad de recursos alternativos. Con base en su jurisprudencia, en la cual sostuvo que el derecho de acceso a los tribunales no es un derecho absoluto, sino que puede estar sujeto a limitaciones, ${ }^{95}$ el TEDH mantuvo que esas limitaciones no deberían restringir el derecho de acceso a los tribunales de tal manera que la esencia misma del derecho se viera afectada. En la opinión de del TEDH, las limitaciones a este derecho tampoco serían compatibles con el Convenio si no persiguen un fin legítimo y si no existe una relación razonable de proporcionalidad entre los medios empleados y el fin que se persigue. Aplicando este análisis de compatibilidad al presente caso, el Tribunal Europeo (porque es nombre proprio y europeo no funciona aquí como adjetivo) consideró que las inmunidades jurisdiccionales son un medio esencial para asegurar el correcto funcionamiento de las OI, a fin de que se mantengan libres de cualquier interferencia unilateral por parte de los gobiernos y concluyó que la correspondiente restricción al derecho de acceso a los tribunales de los individuos en razón del reconocimiento de inmunidades perseguía un fin legítimo. Sin embargo, respecto del requerimiento de proporcionalidad entre el fin perseguido y los medios empleados, el TEDH enfatizó que "un factor determinante para saber si el reconocimiento[...] de las inmunidades es permisible, consiste en conocer si los demandantes

93 Appl No 26083/94 Waite and Kennedy v Germany (1999) ECHR 1999-I (TEDH, Pleno, Sentencia de 18 de febrero de 1999).

94 App No 28934/95 Beer and Regan v Germany (TEDH, Pleno, sentencia de 18 de febrero de 1999).

95 Golder $v$ the United Kingdom (nota 60); Osman v the United Kingdom (nota 60) párr. 147; App No 17101/90 Fayed v the United Kingdom Series A No. 294-B (TEDH, Sentencia de 21 de setiembre de 1994), párr. 65. 
disponían de medios alternativos que protegieran efectivamente sus derechos convencionales". ${ }^{96}$ En el dicho caso, el TEDH consideró que el requisito de proveer mecanismos alternativos de solución de controversias se había cumplido, ya que la Agencia Espacial Europea había establecido una Junta Interna de Apelaciones. A pesar de que algunos académicos criticaron al Tribunal por no revisar -con mayor escrutinio- la eficacia de los recursos alternativos, ${ }^{97}$ estas tres sentencias, Matthews, Waite y Kennedy, y Beer y Regan, marcaron un hito en la construcción de un marco analítico para evaluar la legalidad y legitimidad del reconocimiento de inmunidades a las organizaciones internacionales.

La idea de que un individuo deba recibir una "protección equivalente" dentro de una OI fue precisada posteriormente en el caso Bosphorus, ${ }^{98}$ en el cual el TEDH determinó que un Estado no puede liberarse de sus obligaciones bajo el Convenio mediante la transferencia de sus funciones a una organización ya que esto

[...] absolvería completamente a los Estados Contratantes de sus responsabilidades ante el Convenio en las áreas cubiertas por esa transferencia, lo cual sería incompatible con el objeto y fin del Convenio; igualmente, las garantías del mismo podrían ser limitadas o excluidas a voluntad y por ende serían privadas de su carácter obligatorio y se vería minado el efecto práctico y eficaz de sus garantías [...]. Por ende, se considera que el Estado mantiene la responsabilidad bajo el Convenio respecto de cualesquiera compromisos adquiridos con posterioridad a la entrada en vigor del mismo. ${ }^{99}$

96 Waite and Kennedy v. Germany (nota 93) párr. 68.

97 Jean-François Flauss, "Droit des immunités et protection internationale des droits de l'homme" (2000), en Revue suisse de droit international et de droit européen 299, 323; August Reinisch, "Waite and Kennedy v. Germany, Application No. 26083/94; Beer and Regan v. Germany, Application No. 28934/95” (1999), en 93 American Fournal of International Law 933.

98 Application No. 45036/98, Bosphorus Hava Yollary Turizm ve Ticaret Anonim Sirketi v Ireland ECtHR 2005-VI (TEDH, Pleno, sentencia de 30 de junio de 2005).

99 Ibidem párr. 154. 
Sin hacer alusión alguna a la jurisprudencia Solange de la Corte Constitucional Alemana ni a los otros tribunales que la acogieron, el TEDH aplicó el principio de protección equivalente tal y como fue desarrollado por los tribunales nacionales. Así, la Corte de Estrasburgo sostuvo que cuando un Estado actúa en cumplimiento con sus obligaciones internacionales y con sus obligaciones como Miembro de una OI, dicho acto sólo puede justificarse "siempre y cuando" la OI proteja los derechos fundamentales, tanto en lo que concierne a las garantías sustantivas, así como a los mecanismos que controlan su observancia, de manera equivalente a lo establecido en el Convenio Europeo. Si la OI provee una protección equivalente, se presume que el Estado se ajusta al Convenio cuando implementa las obligaciones jurídicas derivadas de su membresía en dicha organización. ${ }^{100}$

En el desarrollo de su jurisprudencia, el TEDH indicó en el caso Gasparini ${ }^{101}$ que dentro de una OI los Estados tienen la obligación de asegurar que los derechos del Convenio reciban una protección equivalente a la garantizada por el sistema europeo. Sin embargo, posteriormente, el TEDH estableció que los procedimientos internos disponibles para los empleados de la OTAN no eran "manifiestamente insuficientes", y por ende los Estados demandados no incumplían con el requisito de protección equivalente. Por otra parte, el Tribunal Europeo (usado como nombre proprio y no adjetivo) encontró en el caso Michaud ${ }^{102}$ que, debido a que al demandante se le impidió agotar completamente los recursos disponibles dentro de la Unión Europea (UE), el derecho de acceso a los tribunales fue obstaculizado, y por lo tanto la presunción de protección equivalente, establecida en el caso Bosphorus respecto de la UE, no podría

100 Ibidem párr. 155.

101 Application No 10750/03 Gasparini v Italy and Belgium (TEDH, sentencia de 12 de mayo de 2009).

102 App No 12323/11 Michaud v France ECHR 2012 (TEDH, sentencia de 6 de diciembre de 2012). 
aplicarse en ese caso. ${ }^{103}$ En casos más recientes, el TEDH también consideró los estándares de protección de los derechos humanos con respecto de los actos adoptados por la ONU. Dichos casos serán examinados con mayor detalle en la sección 4.3.

En 1999, la CIJ también tuvo la oportunidad de abordar la relevancia de la disponibilidad de recursos jurídicos a lo interno de las OI a la luz de sus inmunidades. En su opinión consultiva Diferencia relativa a la inmunidad judicial de un Relator Especial de la Comisión de Derechos Humanos, ${ }^{104}$ la Corte analizó la obligación de proveer mecanismos internos de reparación como corolario del derecho de la ONU a sus inmunidades. Así, sostuvo que la Organización puede ser responsable por los actos de sus agentes efectuados en su capacidad oficial. Por consiguiente, de acuerdo con la opinión de la Corte, la cuestión de las inmunidades es distinta del deber de indemnizar por daños ocurridos como resultado de los actos oficiales de sus funcionarios, y que los reclamos que emanen de éstos deben ser resueltos de conformidad con los medios apropiados de solución de controversias que deberán ser establecidos por la ONU. ${ }^{105}$ Esto representa ser un avance importante al fallo en el caso Efectos de los Fallos del Tribunal Administrativo de Naciones Unidas en los que se fijan compensaciones, ${ }^{106}$ donde la Corte consideró la obligación de la ONU de proveer medios alternativos de solución de controversias únicamente en el contexto específico de controversias laborales, afirmando que sería “[...] difícilmente compatible con lo expresado en los fines de la Carta sobre la promoción de la libertad y la justicia para los individuos[...] si las Naciones Unidas no provieran a sus pro-

103 Ibidem, párr. 115.

104 Difference Relating to Immunity from Legal Process of a Special Rapporteur of the Commission on Human Rights ([1999] ICJ Reports 62, Opinión Consultiva 29 de abril de 1999).

105 Ibidem, párr. 66.

106 Effect of Awards of Compensation Made by the United Nations Administrative Tribunal [1954] ICJ Reports 47. 
pios funcionarios con un recurso judicial o arbitral para la solución de controversias". ${ }^{107}$ Por consiguiente, la ausencia de recursos en contra de la ONU no solo puede considerarse como una violación a los derechos humanos de los individuos, sino que igualmente se podría considerar que, en lo que atañe a las controversias laborales, también violenta las disposiciones de la Carta de la ONU.

2. REcepción por parte de otras instituciones INTERNACIONALES

La idea de que un Estado debe lograr un equilibrio entre las obligaciones frente a las OI y sus obligaciones frente a los individuos en materia de derechos humanos, ha encontrado apoyo en el mundo académico y se vio reflejada ${ }^{108}$ en el Proyecto de Artículos sobre la Responsabilidad Internacional de las Organizaciones Internacionales (PARIOI), adoptados por la CDI en 2011. ${ }^{109}$ La CDI otorgó a este principio una aplicación general y, citando expresamente los criterios establecidos en Waite y Kennedy y en Bosphorus, estipuló en el Artículo 61 que el Estado miembro de una OI incurre en res-

107 Ibidem, párr. 57.

108 Asociación de Derecho Internacional, Accountability of International Organizations (1996-2004) Final Conference Report, Berlín 2004, 41 y 46, disponible en <http://www.ila-hq.org/en/committees/index.cfm/cid/9> (ultimo acceso en febrero 2013). Vid., también IAn Brownlie, "The Responsibility of States for the Acts of International Organizations" en O. Schachter y M. Ragazzi (eds.), International Responsibility Today: Essays in Memory of Oscar Schachter (Leiden; Boston, Martinus Nijhoff, 2005) 361; Olivier De Schutter, "Human Rights and the Rise of International Organizations: The Logic of Sliding Scales in the Law of International Responsibility" en Jan Wouters y Eva Brems (eds.), Accountability For Human Rights Violations By International Organisations (Intersentia, 2010) 51; Dan Sarooshi, International Organizations and their Exercise of Sovereign Powers (Oxford; New York, Oxford University Press, 2005) International Responsibility Today: Essays in Memory of Oscar Schachter (Leiden; Boston, Martinus Nijhoff, 2005).

109 PARIOI, con comentarios (nota 39) 54 y ss. 
ponsabilidad internacional si aprovechándose de que una organización es competente en relación con la materia de una obligación internacional de ese Estado, elude esa obligación y ocasiona que la OI cometa dicho acto, el cual, si fuera cometido por el referido Estado, constituiría una violación a esa obligación. ${ }^{110}$ Igualmente, en el Artículo 45(2) del PARIOI, la CDI adoptó el requisito de contar con recursos internos que no sólo deben estar disponibles, sino que también deben ser efectivos para las víctimas de violaciones de derechos humanos. ${ }^{111}$ Entre los ejemplos proporcionados por la CDI en el PARIOI se incluyen los recursos que existen dentro de la UE y el tratamiento de un individuo por parte de una OI durante la administración de un territorio. ${ }^{112}$

En su opinión relativa a la Oficina del Alto Representante para Bosnia y Herzegovina, la Comisión de Venecia del Consejo de Europa abordó el tema de la ausencia de recursos jurídicos para la protección de los derechos humanos por parte de una OI que administra un territorio. ${ }^{113}$ La Comisión estableció que los actos del Alto Representante deben cumplir con los estándares internacionales y consideró inaceptable que las decisiones del Alto Representante que afectasen directamente los derechos de los individuos no estuvieran

110 Vid., el comentario al Artículo, donde el pasaje relevante de Waite \& Kennedy es citado literalmente; Ibidem 94.

111 Ibidem 71-74. Sin embargo, a fin de que un recurso sea considerado como efectivo, no es necesario que sea judicial; vid., v. g., ERIKA DE WET, "Holding International Institutions Accountable: The Complementary Role of Non-Judicial Oversight Mechanisms and Judicial Review" (2008), en 9 German Law fournal 1987.

112 PARIOI, con comentarios (nota 39) 73. Sin embargo, el PARIOI también tiene lagunas significativas con respecto a la protección de los derechos humanos; vid., Armin von Bogdandy y Mateja Steinbrück Platise, "DARIO and Human Rights Protection: Leaving the Individual in the Cold" (2012), en 9 International Organizations Law Review 67.

113 European Commission for Democracy through Law, Opinion on the Constitutional Situation in Bosnia and Herzegovina and the Powers of the High Representative, 62 Sesión, CDL-AD (2005) 004, Venecia, 11 y 12 de marzo de 2005. 
sujetas a una audiencia imparcial, o al debido proceso y escrutinio de un tribunal independiente. En la opinión de la Comisión, esto era particularmente problemático, ya que el Alto Representante carecía de legitimidad democrática ante la población de Bosnia y Herzegovina. Tal situación no puede durar para siempre, sino que "vendrá el día en que esas decisiones serán sometidas a un pleno control judicial e impondrán las responsabilidades ante las instancias nacionales adecuadas". ${ }^{114}$ La ausencia de recursos legales para reclamar violaciones a los derechos humanos por parte de las OI también ha sido criticada en el Reporte de la Asamblea Parlamentaria del Consejo de Europa. ${ }^{115}$

La necesidad de proveer un foro alternativo para la protección de los derechos humanos también ha reconocida cada vez más, incluso por las mismas OI. Algunos de los primeros estudios afirmaron que, interpretado a contrario sensu, la disponibilidad de recursos alternativos prevendría que se conculquen los derechos humanos o los estándares constitucionales relativos al derecho de acceso a la justicia de los individuos, y conllevaría a que los tribunales nacionales respetasen las inmunidades de las OI. ${ }^{116}$ La obligación de brindar acceso a los procedimientos de solución de controversias ha sido reconocida de manera más clara en lo que respecta a los funcionarios de las OI. ${ }^{17}$ Hoy en día, ese derecho de los empleados

114 Ibidem, párr. 97.

115 Accountability of international organizations for human rights violations, Report of the Committee on Legal Affairs and Human Rights, Doc. 13370, 17 de diciembre de 2013.

116 CID 'UN Study 1967' (8 de marzo, 5 de mayo y 23 de mayo de 1967) UN Doc A/CN.4/L.118 y Add. 1 + 2, 154; CID 'UN Study 1985' (27 de mayo, 27 de junio y 28 de julio de 1985) UN Doc A/CN.4/L383 y Add. 1.

117 En el caso Chadsey, el Tribunal Administrativo de la OIT interpretó como "principio que cualquier empleado tiene derecho, en caso de una controversia laboral con su patrón, a la salvaguarda de un procedimiento de apelaciones"; Chadsey v Universal Postal Union, ILO Administrative Tribunal, 15 de octubre de 1968, Sentencia No. 122; en Rubio v the Universal Postal Union, el Tribunal Adminis- 
es interpretado por los tribunales administrativos de las OI como un principio jurídico vinculante. ${ }^{118}$ Además de los servidores públicos de las OI, en algunos casos, otras entidades privadas pueden ahora presentar demandas en contra de algunas OI acogiéndose a sus mecanismos internos de solución de controversias. Por ejemplo, las discusiones de los tribunales nacionales sobre la protección de los derechos humanos dentro de la CE contribuyeron de manera importante al desarrollo de los recursos legales actualmente disponibles en la UE. ${ }^{119}$ Desde 1993, los particulares también pueden presentar ciertas demandas contra el Banco Mundial (BM), ya que se estableció un Panel de Inspección con el fin de evaluar si una acción u omisión del Banco afecta directamente los derechos o intereses de los demandantes, según los procedimientos y políticas operativas del Banco. ${ }^{120}$ Este ejemplo fue retomado por el Banco

trativo sostuvo posteriormente que la negativa de dirimir el presente caso constituiría una denegación del debido proceso y contrario a los principios generales, a la Declaración Universal de Derechos Humanos y a la Convención Americana de Derechos Humanos, supra nota 64.

118 Ejemplos anteriores incluye Waghorn v ILO, [1957] ILOAT Sentencia No. 28; Mendaro v IBRD, 1985 World Bank Administrative Tribunal Reports, Sentencia No. 26, p. 9; Franks v EPO, [1994] ILOAT Sentencia No. 1333.

119 Con respecto al proceso de accesión de la UE al Convenio Europeo de Derechos Humanos, también se ha argumentado que "[d] esde una perspectiva de los ciudadanos, la accesión garantizará a cualquier persona que reclame ser víctima de una violación al Convenio por una institución u organismo de la Unión la posibilidad de presentar una queja en contra de la Unión ante la Corte de Estrasburgo bajo las mismas condiciones que aquellos que presentan quejas en contra de los Estados Miembros", vid., Viviane Reding, Vice-Presidente de la Comisión Europea responsable de Justicia, Derechos Fundamentales y Ciudadanía, The EU's accession to the European Convention on Human Rights: Towards a stronger and more coherent protection of human rights in Europe, Bruselas, 18 de marzo de 2010, disponible en: <http://ec.europa.eu/commission_2010-2014/reding/pdf/ speeches/speech_20100318_1_en.pdf>, (último acceso en febrero 2013).

120 Para una visión general de la labor del Panel vid., Accountability at the World Bank, The Inspection Panel, 10 Years On, The International Bank for Reconstruction and Development/The World Bank, 2003, vid., también la página web del 
Interamericano de Desarrollo, el Banco Asiático de Desarrollo, el Banco Europeo de Reconstrucción y Desarrollo y el Banco Africano de Desarrollo, los cuales han establecido sus respectivos páneles internos de inspección. ${ }^{121}$ Después de que el Panel Interno de Inspección del BM fue criticado por que sus recursos internos no cumplían con el estándar de efectividad, ${ }^{122}$ en 2011 complementó su mecanismo interno con un procedimiento de sanciones, el cual opera en casos de corrupción y fraude cometidos por individuos y compañías involucrados en las actividades del Banco. Mientras que este proceso de sanciones es limitado en cuanto a la admisibilidad ratione personae y materiae de las demandas, algunos autores consideran al mecanismo como ejemplo a adoptar por las OI, ya que contiene varios elementos propios de los mecanismos judiciales de solución de controversias. ${ }^{123}$

Este avance de carácter procesal, el cual da cabida a las demandas de los particulares, no implica necesariamente que las OI reconozcan estar obligadas por los derechos humanos o por el componente internacional del Estado de Derecho. No obstante, se pueden encontrar muestras de aceptación en los documentos oficiales de las OI, tal como en la Declaración de las Naciones Unidas sobre la Reunión de

Panel de Inspección en: <http://web.worldbank.org/WBSITE/EXTERNAL/ EXTINSPECTIONPANEL/0,, menuPK:64132057 pagePK:64130364 piPK:64132056 theSitePK:380794,00.html>, (último acceso en febrero 2013).

121 Para una visión general vid., S. I. Skogly, The Human Rights Obligations of the World Bank and the International Monetary Fund (Cavendish Publishing Ltd, 2001) $180-185$.

122 Ibidem 180-181; S. R. Roos, "The World Bank Inspection Panel in its Seventh Year: An Analysis of its Process, Mandate and Desirability with special reference to the China (Tibet) case", en J. A. Frowein y R. Wolfrum (eds.) Max Planck Yearbook of United Nations Law, Vol. 5, 2001, 473-521; A. BuIRA, (ed.) Challenges to the World Bank and IMF, Antham Press, 2003; K Wellens, Remedies against International Organizations, Cambridge University Press, 2004, pp. 185 y ss.

123 Laurence Boisson de Ghazournes y Edouard Fromageau, "Balancing the Scales: The World Bank Sanctions Process and Access to Remedies" (2012), en 23 European Fournal of International Law 963. 
Alto Nivel de la Asamblea General sobre el Estado de Derecho en los planos nacional e internacional, la cual establece que

[...] el Estado de Derecho se aplica a todos los Estados por igual y a las organizaciones internacionales, incluidas las Naciones Unidas y sus órganos principales, y que el respeto y la promoción del Estado de Derecho y la justicia deben guiar todas sus actividades y conferir previsibilidad y legitimidad a sus acciones. También reconocemos que todas las personas, instituciones y entidades, públicas y privadas, incluido el propio Estado, están obligadas a acatar leyes justas, imparciales y equitativas, y tienen derecho a igual protección de la ley, sin discriminación. ${ }^{124}$

Por consiguiente, puede observarse que las contestaciones de las cortes nacionales, con el apoyo de varios órganos internacionales, contribuyen a elevar el nivel de respeto de los derechos humanos por parte de las OI. Sin embargo, que estas muestras de aceptación se desarrollen en una tendencia generalizada dependerá de la práctica de los tribunales nacionales y el diálogo que establezcan con otras cortes e instituciones internacionales.

\section{De LA RECEPCIÓN A LA INTERACCIÓN}

Parece ser que las cortes y otras instituciones internacionales están listas para abordar el cuestionamiento planteado por algunas cortes nacionales sobre si el régimen restrictivo de las inmunidades de las OI también debe ser aplicado a la ONU. Ciertamente, aún no se termina de definir si se debe aplicar un régimen uniforme a todas las OI, sin importar las diferencias entre su composición, su estructura institucional, su posición jurídica, sus funciones, poderes y mandatos. En ese sentido, podría considerarse a la ONU como especial, ya que ocupa un lugar importante en la comunidad jurídica internacional debido a su particular mandato

124 UN Doc. A/67/L.1, párr. 2; otros ejemplos incluyen el Reporte del Comité de Asuntos Jurídicos y Derechos Humanos de la Asamblea Parlamentaria del Consejo Europeo, Doc. 13370, 17 de diciembre de 2013. 
y facultades. Por ejemplo, con respecto a los actos y omisiones de la MINUK y las fuerzas KFOR de la OTAN que operan en Kosovo, de conformidad con una resolución del CS de la ONU, el TEDH apuntó en los casos Behrami y Saramati ${ }^{125}$ que los poderes confiados a la Organización bajo el Capítulo VII de la Carta de la ONU eran fundamentales para la misión de dicha OI para mantener la paz y seguridad internacionales. Por ende, la implementación que los Estados Miembros realizan no debería estar sujeta al escrutinio del TEDH, ya que esto podría comprometer la conducción efectiva de las operaciones de la ONU. ${ }^{126}$ Esto conllevó a que la Suprema Corte neerlandesa concluyera en el caso Mothers of Srebrenica ${ }^{127}$ que los actos y omisiones de las Fuerzas de Protección de Naciones Unidas, las fuerzas destacadas en la Antigua Yugoslavia bajo mandato del capítulo VII para el mantenimiento de la paz, no podrían ser examinados bajo el estándar de Waite y Kennedy. ${ }^{128}$ Más bien, la Corte Suprema determinó que las inmunidades de la ONU deberían reconocerse a pesar de que no existiere recurso jurídico alguno para los individuos cuyos derechos hubieran sido presuntamente conculcados por la ONU. En ese sentido, el la Corte Suprema declaró a las inmunidades de esa Organización como absolutas. ${ }^{129}$ En procesos legales subsecuentes ante el TEDH, el Tribunal de Estrasburgo respaldó la decisión de la Corte Suprema de los Países Bajos. ${ }^{130}$ A pesar de que concedía que las víctimas del genocidio en Srebrenica no contaban con recurso jurídico alguno ni ante los tribunales nacionales ni ante

125 Appl Nos 71412/01, y 78166/01 Behrami and Behrami v France; Saramati v France, Germany and Norway (2007) (TEDH, Decisión de admisibilidad de 2 de mayo de 2007).

126 Ibidem párr. 149.

127 Mothers of Srebrenica $v$ Netherlands and United Nations, Final appeal judgment (nota 16).

128 Con respecto al caso Waite and Kennedy, vid., Sección IV(A).

129 Mothers of Srebrenica $v$ Netherlands and United Nations, Final appeal judgment (nota 16) párr. 4.3.6.

130 App No 65542/12 Stichting Mothers of Srebrenica and Others v The Netherlands (TEDH, sentencia de 11 de junio de 2013). 
la ONU, el TEDH se rehusó a aplicar el estándar desarrollado en su sentencia Waite y Kennedy. Al contrario, reafirmó la postura tomada en los casos Behrami y Saramati, y consideró que si permitiera que las operaciones de la ONU ejecutadas bajo el Capítulo VII de la Carta pudieren ser sometidas a la jurisdicción de las cortes nacionales abriría la puerta para que los Estados, a través de sus tribunales, pudieran interferir en el cumplimiento de la misión principal de la ONU en el campo de la seguridad y la paz internacionales.

Mientras que el TEDH decidió no exigir el requisito de protección alternativa respecto de las inmunidades de la ONU, sí aplicó este criterio en otros casos presentados contra la implementación a nivel nacional de actos de la ONU. Los dos casos relevantes aluden a la ejecución de medidas dictadas por el CS sobre sanciones selectivas adoptadas bajo resolución del Capítulo VII de la Carta, y fueron influenciados por la práctica de los tribunales nacionales en torno a la jurisprudencia Solange de la Corte Constitucional de Alemania. Expresamente, el TEDH también fue influenciado por la sentencia del Tribunal de Justicia de la Unión Europea (TJUE) en el caso Kadi, en donde la TJUE estableció que la implementación de las sanciones selectivas del CS de la ONU violaría los derechos humanos reconocidos en el orden jurídico comunitario europeo, en particular el derecho a un juicio justo y el derecho a un recurso jurídico. ${ }^{131}$ Así, en el caso $\mathrm{Nada},{ }^{132}$ el TEDH determinó que las normas de la ONU no impiden el control judicial de los actos que implementan, a nivel nacional, las decisiones adoptadas por el C.S del mandato del Capítulo VII de la Carta. Por consiguiente, sostuvo que Suiza violó

131 Casos C-402/05 P y C-415/05 P Kadi and Al Barakaat International Foundation $\checkmark$ Council of the European Union and Commission of the European Communities (2008) [2008] ECR I-06351 (TEJ, Sentencia de 3 de setiembre de 2008, 'Kadi I (TEJ)'). Vid., también Juliane Koкотт y Christoph Sobotta, "The Kadi Case-Constitutional Core Values and International Law-Finding the Balance?" (2012), en 23 European Journal of International Law 1015.

132 Appl No 10593/08 Nada v Switzerland (2012) (TEDHR, Pleno, Sentencia de 12 de setiembre de 2012). 
el derecho de acceso a los tribunales conferido por el Convenio, ya que no brindó al demandante los recursos efectivos para oponerse a la implementación de las sanciones impuestas por el CS. Posteriormente, en el caso de Al-Dulimi et Montana Management, ${ }^{133}$ el TEDH estableció que la ONU no aseguró una protección equivalente de los derechos humanos. Por ende determinó que la presunción establecida en el caso Bosphorus, la cual considera que la implementación de un acto de una OI realizada por un Estado Miembro es acorde con lo establecido en el Convenio Europeo, no era aplicable respecto de la ONU. Por ende, se podría concluir de lo anterior que el TEDH cuenta con que los tribunales nacionales revisen el cumplimiento con los derechos humanos de los actos de las OI y únicamente permitan la implementación de aquellos actos que no violen el derecho de los individuos a un recurso legal. Así, a pesar de que el TEDH mismo eventualmente no es competente para controlar los recursos internos disponibles dentro de la ONU, obliga a las cortes nacionales a llevar a cabo dicho control. Ciertamente, esto parece ser una invitación a los tribunales nacionales para complementar el control judicial del TEDH y compensar la ausencia de jurisdicción del Tribunal Europeo sobre las OI.

Incentivos similares para realizar este control judicial nacional son también impulsados, no solo por parte de las cortes internacionales, sino también por otras OI. Por ejemplo, respecto a las sanciones selectivas del CS de la ONU, la Asamblea General de la ONU (AG) "[i]nsta a los Estados a que, velando por el pleno cumplimiento de sus obligaciones internacionales, incluyan las debidas garantías de los derechos humanos en sus procedimientos nacionales para la inclusión de personas y entidades en la lista con miras a combatir el terrorismo". ${ }^{134}$ De este modo, los procedimientos nacionales in-

133 App No 5809/08 Al-Dulimi and Montana Management Inc v Switzerland (TEDH, Sentencia de 26 de noviembre de 2013).

134 Resolución 63/185 de la AG de la ONU, Protección de los derechos humanos y las libertades fundamentales en la lucha contra el terrorismo (3 marzo 
cluyen procesos jurisdiccionales. ${ }^{135}$ El Relator Especial de Naciones Unidas se adhirió a ese llamado expresando que debido a

[Q]ue en el ámbito de las Naciones Unidas no existe un examen independiente[...], las decisiones judiciales o cuasi judiciales del Consejo de Seguridad tienen carácter preliminar y no definitivo, [y] es esencial que las personas y entidades incluidas en la Lista puedan someter a un examen del sistema judicial nacional toda medida destinada a aplicar las sanciones. ${ }^{136}$

Esta tendencia puede ser considerada como un reflejo de la interdependencia y la interacción entre las cortes nacionales y las instituciones internacionales en la protección de los derechos humanos y la promoción del Estado de Derecho en el plano internacional.

V. ESBOZANDO UN MARCO NORMATIVO PARA LA INTERACCIÓN ENTRE LAS CORTES NACIONALES $Y$ LAS INSTITUCIONES INTERNACIONALES

\section{Interdependencia de las fuentes del Derecho}

Un breve repaso de las decisiones de las cortes y otras instituciones internacionales podría sugerir que la necesidad de revisar el alcance de las inmunidades otorgadas a las OI se origina en el seno de los tribunales nacionales. Sin embargo, como se señaló en la sección

2009) UN Doc A/RES/63/185 párr. 20 (énfasis añadido).

135 A Peters, 'Commentary to Article 25,' en B Simma (ed.), Commentary of the UN Charter, 761-854, 841 .

136 Informe del Relator Especial sobre la promoción y la protección de los derechos humanos y las libertades fundamentales en la lucha contra el terrorismo, UNGA A/65/258 (6 de agosto de 2010) 20, párr. 58. La expresión original del Relator Especial en inglés inicia con "as long as", haciendo una clara alusión a la jurisprudencia Solange. Sin embargo, la traducción oficial de la ONU al español prescinde de ella, perdiéndose la referencia a la jurisprudencia de la Corte Constitucional Alemana. [N. T.] 
anterior, tal esfuerzo parece ser el compromiso común de los tribunales nacionales e internacionales, así como de otras instituciones. Por ejemplo, después de que el TEDH emitió su sentencia en el caso Waite y Kennedy, las cortes nacionales tuvieron un mayor ímpetu así como un fundamento jurídico para examinar si era posible, y bajo qué condiciones, negar las inmunidades a las OI. Incluso, mientras que muchas de las decisiones de los tribunales locales que abordaron el derecho de acceso a la justicia de los empleados de las OI fueron anteriores a la sentencia de Waite y Kennedy del TEDH, tales decisiones nacionales reiteraron la opinión de la CIJ en Efectos de los Fallos del Tribunal Administrativo de Naciones Unidas en los que se fijan compensaciones, en donde la Corte determinó la obligación de la ONU de proveer recursos jurídicos para sus propios funcionarios.

Tal y como se demostró en esos ejemplos, los alcances de las inmunidades y las obligaciones que emanan de éstas para los Estados y las OI han sido moldeadas por el diálogo entre los tribunales nacionales e internacionales. Cada uno de éstos ha aportado un fundamento jurídico para que, por una parte, los tribunales nacionales puedan implementar las decisiones de las cortes internacionales y, por otra, las decisiones de los tribunales nacionales puedan producir efectos jurídicos en el derecho internacional y puedan ser tomadas en cuenta por las cortes internacionales. Por ende, a nivel nacional, la práctica de los tribunales nacionales fue guiada y, en algunos aspectos, determinada por el derecho internacional de los derechos humanos, tal y como fue interpretado por las cortes internacionales, en particular si se consideran las decisiones del TEDH sobre las limitaciones injustificadas al derecho humano de acceso a los tribunales y el derecho a un recurso jurídico. Los tribunales nacionales deben cumplir con las decisiones de las cortes internacionales de acuerdo con el respectivo instrumento constitutivo de esos tribunales, ${ }^{137}$ así como de conformidad con el Artículo 27 de la

137 Vid., v. g., el Artículo 46 del Convenio Europeo de Derechos Humanos y el Artículo 59 del Estatuto de la CIJ. 
Convención de Viena sobre el Derecho de los Tratados, ${ }^{138}$ sin que se pueda justificar el incumplimiento de sus obligaciones internacionales oponiendo derecho nacional, incluyendo las normas constitucionales. Incluso, las decisiones de los tribunales internacionales y europeos no solo producen efectos jurídicos para los Estados que son partes en una controversia (efecto inter partes), sino que afectan las expectativas normativas de todos los Estados que potencialmente puedan ser partes en controversias similares. ${ }^{139}$

A nivel internacional, las decisiones de las cortes nacionales son relevantes para los tribunales internacionales en el sentido de que plasman parte de la práctica de los Estados y, por lo tanto, son consideradas como evidencia del derecho consuetudinario internacional, el cual debe ser aplicado por los tribunales internacionales. Asimismo, las cortes nacionales también determinan los principios generales del derecho que los tribunales internacionales aplican en la toma de decisiones. Así, según el Artículo 38 del Estatuto de la CIJ, las decisiones judiciales de las cortes nacionales son medios auxiliares para determinar el derecho internacional. Por ende, aun en las situaciones en que parece que los tribunales nacionales meramente están cumpliendo con una obligación internacional, éstos necesariamente también interpretan esas obligaciones y, consecuentemente, contribuyen sistemáticamente al desarrollo del derecho internacional. De este modo, las sentencias de las cortes nacionales no son únicamente hechos que son retomados por los tribunales internacionales, sino que también cumplen una función legal en cuanto a que pueden determinar, de manera definitiva, los dere-

138 Convención de Viena sobre el Derecho de los Tratados (nota 49) Art. 27.

139 von Bogdandy y Venzke, In wessen Namen? (nota 86). Vid., también la Opinión Disidente del Juez Sir Robert Jennings en Continental Shelf (Libyan Arab Jamahirija v. Malta), Demanda sobre la intervención, Sentencia, ICJ Reports 1984, p.3, y las declaraciones del Juez Simma en Accordance with International Law of the Unilateral Declaration of Independence in Respect of Kosovo, ICJ Reports 2010, p. 403. 
chos y obligaciones legales bajo el derecho internacional. ${ }^{140}$ Por lo tanto, cada vez son más los académicos que consideran que las cortes nacionales son agentes del orden jurídico internacional. ${ }^{141}$ El cuestionamiento a las inmunidades de las OI realizado por las cortes nacionales, y examinado en este capítulo, es un gran ejemplo del papel que los tribunales nacionales han desempeñado en la aplicación, interpretación y desarrollo del derecho internacional.

2. SeParación de Poderes y EL PRINCIPIO de SUbSIDIARIEDAD

El cuestionamiento a las inmunidades debe ser visto como parte de una serie de contestaciones a la legitimidad de las OI y el derecho internacional en general. ${ }^{142}$ En este contexto, el respeto a los de-

140 André Nollkaemper, National Courts and the International Rule of Law (Oxford; New York, Oxford University Press, 2011), pp. 8-10.

141 Christoph Schreuer, Die Behandlung internationaler Organakte durch staatliche Gerichte (Berlin, Duncker und Humblot, 1977); Antonio Cassese, "Remarks on Scelle's Theory of Role Splitting (dedoublement fonctionnel) in International Law" (1990), en 1 European Fournal of International Law 210, 210; DeIRdRE CurTiN y André Nollkaemper, "Conceptualizing Accountability in International and European Law" (2005), en 36 Netherlands Yearbook of International Law 3; YUvAL Shany, "Dédoublement fonctionnel and the Mixed Loyalties of National and International Judges" en F. Fontaneldi, G. Martinico y P. Carrozza (eds.), Shaping Rule of Law Through Dialogue: International and Supranational Experiences (Groningen, Europa, 2010) 27.

142 Special Issue: The Exercise of Public Authority by International Organizations, supra nota 12, A. Peters, "Compensatory Constitutionalism: The Function and Potential of Fundamental International Norms and Structures", en Leiden Fournal of International Law 19 (2006) 579-610; J. Habermas, "Konstitutionalisierung des Völkerrechts und die Legitimationsprobleme einer verfassten Weltgesellschaf", en W. BRUGGer et al., (eds.), Rechtsphilosophie im 21. Fahrhundert (2008) S. Chesterman, "UNaccountable? The United Nations, Emergency Powers and the Rule of Law", en 42 Vanderbilt fournal of Transnational Law (2009) 1509-1541; G. HAFner, "Can International Organizations be controlled? Accountability and Responsibility", en 97 Proceedings of the Annual Meeting of the American Society of International Law (2003) 236- 240. 
rechos humanos puede ser considerado como uno de los criterios para brindar legitimidad los actos internacionales. De este modo, se ha planteando la necesidad de desacatar normas internacionales cuando representen violaciones lo suficientemente serias a principios normativos, tales como el principio procesal de la adecuada participación, la rendición de cuentas y la protección de los derechos humanos fundamentales. ${ }^{143} \mathrm{El}$ común denominador de estas contestaciones es la búsqueda del Estado de Derecho en el plano internacional, y el principio que señala que cualquier ejercicio de autoridad soberana, incluyendo el de aquellos actos ejecutados por las OI, debe basarse en la autoridad conferida por las normas y, consecuentemente, controladas por las mismas. ${ }^{144}$ El Estado de Derecho en el plano internacional requiere, inter alia, que el ejercicio de poder de una autoridad pública internacional se ajuste a los estándares fundamentales de derechos humanos. ${ }^{145}$ Asimismo, en

143 Cfr. Kumm, "The Legitimacy of International Law" (nota 47) 917; Ernest A. Young, "The Trouble with Global Constitutionalism" (2003) 38 Texas International Law fournal 527; JeD Rubenfeld, "The Two World Orders" (2003) The Wilson Quarterly 22. Vid., también el razonamiento de las cortes nacionales e internacionales en los casos mencionados anteriormente como Solange I, Kadi y Nada.

144 von Bogdandy, Dann y Goldmann, "Developing the Publicness of Public International Law: Towards a Legal Framework for Global Governance Activities" (nota 12); Gianluigi Palombella y Neil Walker, Relocating the Rule of Law (Oxford, Hart, 2009); Mattias Kumm, "International Law in National Courts: The International Rule of Law and the Limits of the Internationalist Model" (2003), en 44 Virginia Fournal of International Law 19, 22; Nollkaemper, National Courts and the International Rule of Law, (nota 140).

145 H. Keller y A. Fischer, "The UN Anti-terror Sanctions Regime under Pressure" (2009), en 9 Human Rights Law Review 257; ERIKA De Wet y André Nollkaemper (eds.), Review of the Security Council by Member States (Intersentia, 2003). Recent resolutions of the United Nations Security Council, notably those resulting in the freezing of assets of individuals and organisations suspected of involvement in international terrorism, have had far-reaching consequences for Member States and individuals. In addition, they might conflict with international human rights standards that are binding on the Security Council. 
caso de que la autoridad contravenga sus obligaciones legales, ya fueren internacionales o nacionales, ${ }^{146}$ debe hacérsele responsable por sus actos con base en lo determinado por las normas jurídicas. En particular, este último requisito evidencia uno de los problemas estructurales del derecho internacional, a saber, la ausencia de un poder judicial internacional independiente y coercitivo que pueda revisar las violaciones a los derechos humanos cometidas por las OI.

El papel que debería corresponder a los jueces internacionales de controlar el cumplimiento de los derechos humanos por parte de las OI ha sido reclamado de manera creciente por los tribunales nacionales. Mientras que las cortes locales siempre han sido el primer foro para adjudicar sobre los derechos y obligaciones de los particulares, éstas también se están convirtiendo en el primer foro para atender sus reclamos internacionales, haciendo que surjan como sujetos del marco jurídico internacional. ${ }^{147}$ De este modo determinan, interpretan y aplican los derechos humanos y el Estado de Derecho internacional a las OI, y ejercen una función complementaria que usualmente es encomendada a los tribunales internacionales. Así, los tribunales nacionales e internacionales se complementan uno con el otro para la protección de los derechos humanos. Es cierto, puede parecer casi paradójico que mientras los tribunales internacionales vigilan la observancia de los derechos humanos ejercida por las cortes y otras autoridades nacionales, los jueces nacionales vigilan la observancia de los derechos humanos por parte de las autoridades internacionales. Así, las deficiencias en la protección de los derechos humanos y el Estado de Derecho, y más ampliamente, las deficiencias en los pesos y contrapesos entre las diferentes autoridades en un sistema jurídico, son compensadas

146 Sobre la responsabilidad de las organizaciones internacionales en el derecho nacional vid., August Reinisch, "Accountability of International Organizations According to National Law"(2005), en 36 Netherlands Yearbook of International Law 119.

147 Nollkaemper, National Courts and the International Rule of Law (nota 140) 12. 
por otro sistema jurídico. Lo particular en este desarrollo es que la separación de poderes no sólo está siendo establecida entre las autoridades pertenecientes al mismo orden jurídico, sino que también entre las autoridades pertenecientes a distintos órdenes jurídicos. Por lo tanto, este desarrollo presenta una nueva etapa en la creciente interdependencia entre diferentes sistemas normativos.

A pesar de la función complementaria que ejercen las cortes nacionales para proteger los derechos humanos en contra de las violaciones cometidas por las OI, tales tribunales difícilmente pueden ser considerados como el foro más apropiado para adjudicar estos temas. Una de las razones es que las OI pueden ser sometidas a interferencias y al control unilateral por parte del Estado-foro, lo que puede afectar su independencia y funcionamiento. ${ }^{148}$ Otro inconveniente es que la elección de los tribunales nacionales como foro para dirimir estas controversias puede resultar en una jurisprudencia fragmentada y desigual, aún se trate de la misma OI y del mismo objeto materia de controversia. Esto puede comprometer tanto las OI, así como también la certeza legal en cuanto a la protección de las víctimas. ${ }^{149}$ En casos de controversias laborales entre las organizaciones y sus empleados, las cortes nacionales podrían también carecer de la experiencia suficiente para aplicar el derecho

148 Ésta ha sido la razón principal para concluir tratados sobre privilegios e inmunidades; vid., E. H. FEDdER, "The Functional Basis of International Privileges and Immunities: A New Concept in International Law and Organization", (1960) Am. U L Rev 9, 60-69. En ese sentido, también la renuncia de las inmunidades está reglamentada; para una disposición estándar vid., el Artículo IV, Sección 14 de la Convención sobre Prerrogativas e Inmunidades de las Naciones Unidas, la cual estipula que "[s]e concederán privilegios e inmunidades a los representantes de Miembros no en provecho propio sino para salvaguardar su independencia en el ejercicio de sus funciones en relación con las Naciones Unidas".

149 Esto acarrearía mayor fragmentación con respecto a la obligación de los Estados de dar cumplimiento a las obligaciones en derechos humanos; vid., en sentido positivo, Laurence R. Helfer, "Forum Shopping for Human Rights" (1999), en 148 University of Pennsylvania Law Review 285. 
administrativo internacional. ${ }^{150}$ Del mismo modo, incluso en los casos en donde las inmunidades no son un problema, por ejemplo cuando se produce la respectiva renuncia por parte de una OI, la cuestión persiste sobre cuáles medidas de ejecución pueden ser consideradas como apropiadas para la implementación de la sentencia de la corte nacional. ${ }^{151}$ Sin embargo, la mayor inquietud es que si a cada Estado se le permite examinar tanto los actos de las OI, como los actos jurídicos nacionales que los implementan internacionales, la obligatoriedad de los actos internacionales podría ser puesta en duda. ${ }^{152}$ Por consiguiente, la protección de los derechos humanos contra las violaciones de las OI a nivel local no termina de satisfacer y la acción a nivel internacional es necesaria.

Por ende, el papel de los tribunales internacionales en la solución de controversias relacionadas con las OI debe ser considerado únicamente como subsidiario y de última instancia. Así, propongo que el ejercicio de los poderes de adjudicación ejercido por las cortes nacionales se guíe por el principio de subsidiariedad. Dicho principio ha sido fundamental en el constitucionalismo europeo, e indica que en las áreas que no son competencia exclusiva de la UE, ésta actuará sólo si los objetivos perseguidos por la UE no pueden ser alcanza-

150 August Reinisch, "The Immunity of International Organizations and the Jurisdiction of their Administrative Tribunals" (2008), en 7 Chinese Fournal of International Law 285.

151 Por ende, los tratados de privilegios e inmunidades de las organizaciones internacionales hacen una diferencia entre la renuncia de las inmunidades para someterse a la jurisdicción de una corte nacional con aquella de la inmunidad para la ejecución. Por ello, el Artículo II, Sección 2 dispone, de igual manera que otros tratados de inmunidades, que "[s]e entiende, sin embargo, que esa renuncia no se aplicará a ninguna medida judicial ejecutoria".

152 Con respecto a la revisión de los actos adoptados por el CS de ONU vid., Anne Peters, "Article 25", en B. Simma et al., (eds.), The Charter of the United Nations: A Commentary, vol I ( $3^{\circ}$ ed., Oxford University Press, 2012) 840. 
dos por los Estados Miembros. ${ }^{153}$ El principio de subsidiariedad es también uno de los principios centrales que apuntalan el sistema de protección de los derechos humanos bajo el Convenio Europeo de Derechos Humanos. ${ }^{154}$ En dicho contexto, esto implica que la tarea principal de asegurar el respeto de los derechos humanos, tal y como son estipulados en el Convenio, recae en los Estados, y que el TEDH puede y debe intervenir sólo si las autoridades nacionales no cumplen con esa tarea. ${ }^{155}$ Mientras que la subsidiariedad no ha sido ampliamente reconocida como uno de los principios generales del derecho internacional,sí ha sido invocada cada vez más como un principio político y jurídico que debe gobernar la asignación y ejercicio de los poderes de las organizaciones internacionales, así como en el marco de la gobernanza compuesta por diversos niveles (gobernanza multinivel). ${ }^{156}$ Con el propósito de mediar entre la tendencia del nivel de gobernanza de arriba de imponer una unidad centralizada, y la tendencia del nivel de gobernanza de abajo de proteger las diferencias locales, el principio establece la preferencia por el nivel de gobernanza más bajo. Por consiguiente, se pretende proteger la autonomía de los individuos, la identidad cultural, la gobernanza democrática, la soberanía nacional y la eficiencia. ${ }^{157}$ Por lo tanto, la

153 Artículo 5(3) del Tratado de la Unión Europea y Protocolo (No. 2) sobre la Aplicación de los principios de subsidiariedad y proporcionalidad.

154 Sobre el principio de subsidiariedad, vid., capítulos 9 (Birgit Peters) y 12 (Machiko Kanetake) en M. Kanetake y A. Nollkaemper, (eds.) The Rule of Law at the National and International Levels: Contestations and Deference (Hart Publishing, Oxford).

155 Conferencia de Alto Nivel sobre el Futuro del Tribunal Europeo de Derechos Humanos, Declaración de Interlaken de 19 de febrero de 2010.

156 KumM, "The Legitimacy of International Law" (nota 2); ANDrEAS Føllesdal, "Subsidiarity" (1998), en 6 Journal of Political Philosophy 231; PaOlo G. Carozza, "Subsidiarity as a Structural Principle of International Human Rights Law" (2003), en 97 American Fournal of International Law 38.

157 Vid., Kees van Kersbergen y Bertjan Verbeek, 'The Politics of Subsidiarity in the European Union' (1994) 32 JCMS: Fournal of Common Market Studies 215. Los 
gobernanza en el nivel superior puede actuar únicamente respecto de los intereses que no pueden ser realizados en el nivel de la gobernanza respecto de los intereses que no pueden ser realizados. ${ }^{158}$

Tal y como la práctica nacional e internacional discutida en este trabajo sugiere, aun cuando los poderes y las competencias han sido transferidos hacia un nivel de gobernanza superior, como lo es hacia una OI, las cortes nacionales no están dispensadas de ejercer el control judicial en dicho ámbito jurídico. Por lo tanto, a pesar de que la responsabilidad principal de asegurar el respeto de los derechos humanos, y el derecho a un recurso jurídico en particular, haya sido transferida hacia una OI, las cortes nacionales, al menos de manera limitada, pueden y deben continuar con el control judicial de los actos de las OI y su implementación en el plano doméstico a fin de garantizar que los individuos no sean privados de los recursos legales mediante los cuales puedan presentar reclamos en contra de los actos de las OI. Así, el principio de subsidiariedad podría legitimar a las cortes nacionales a desconocer las inmunidades de las OI y ejercer su jurisdicción sobre éstas "siempre y cuando" los mecanismos internacionales de solución de controversias, incluyendo los recursos internos disponibles dentro de las OI, no cumplan con los estándares de efectividad para la protección de los derechos humanos.

\section{vi. Conclusión}

Mientras que el "diálogo judicial", la "fertilización cruzada" y otras nociones describen la influencia que las cortes nacionales e internacionales tienen unas sobre las otras, el impacto de los tribunales

autores argumentan que el aparente consenso sobre el concepto de subsidiariedad ha sido únicamente obtenido mediante la ofuscación.

158 I. Feichtner, "Subsidiarit", en R. Wolfrum (ed.), The Max Planck Encyclopedia of Public International Law, Oxford University Press, Oxford, 2008-, versión en línea, <www.mpepil.com> (último acceso febrero 2013); G. A. Bermann, "Taking Subsidiarity Seriously: Federalism in the European Community and the United States" (1994), en 94 ColumLRev 331- 456. 
nacionales sobre las instituciones internacionales no ha sido investigado con la misma profundidad. Claro está, la interacción entre las autoridades judiciales nacionales e internacionales ha sido más intensa, en particular si se compara con el papel secundario que las instituciones internacionales habían reconocido a los tribunales nacionales en tiempos anteriores. Sin embargo, esto parece estar cambiando. No solamente las cortes nacionales están ganado una posición de mayor igualdad vis-à-vis los tribunales internacionales, sino que también están fortaleciendo su posición jurídica y política vis-à-vis las OI en general. Debido a la ausencia de controles judiciales para la revisión de los actos de las OI en el plano internacional, a las cortes locales se les encomienda cada vez más la tarea de complementar la labor jurisdiccional internacional para examinar la legalidad y legitimidad de los actos de las OI, así como de su implementación a nivel nacional. Por lo tanto, esta forma nacional de control judicial no puede ser vista como un mero acto unilateral de un Estado, sino como una labor que es encomendada a los tribunales nacionales por las cortes y otras instituciones internacionales. ${ }^{159}$ Así, el control jurisdiccional descentralizado de los actos adoptados por las OI refleja también una característica general del derecho internacional, esto es, que se crea, aplica y cumple de forma descentralizada. No obstante, ya que el control de los actos de las OI implica una serie de dificultades, el desafío a las inmunidades de las OI deberá ser únicamente utilizado de manera temporal y residual, sería únicamente cuando y mientras que, las víctimas a las que alguna OI les conculcó sus derechos humanos, no cuenten con algún mecanismo de protección alternativo.

159 Vid., también Peters, "Article 25" (nota 152) 842, donde la autora argumenta que el control jurisdiccional indirecto de las decisiones del CS de la ONU por parte de las cortes nacionales no viola el Artículo 25 de la Carta de la ONU. 